\title{
Disruption and Overexpression of the Gene Encoding ACC (1-Aminocyclopropane-1-Carboxylic Acid) Deaminase in Soil-Borne Fungal Pathogen Verticillium dahliae Revealed the Role of ACC as a Potential Regulator of Virulence and Plant Defense
}

\author{
Maria-Dimitra Tsolakidou, ${ }^{1,+}$ lakovos S. Pantelides, ${ }^{1}$ Aliki K. Tzima, ${ }^{2}$ Seogchan Kang, ${ }^{3}$ \\ Epaminondas J. Paplomatas, ${ }^{2}$ and Dimitris Tsaltas ${ }^{1}$ \\ ${ }^{1}$ Department of Agricultural Sciences, Biotechnology and Food Science, Cyprus University of Technology, 3603 Limassol, \\ Cyprus; ${ }^{2}$ Laboratory of Plant Pathology, Agricultural University of Athens, 75 lera Odos, 11855, Athens, Greece; and \\ ${ }^{3}$ Department of Plant Pathology \& Environmental Microbiology, The Pennsylvania State University, University Park, \\ PA 16802, U.S.A.
}

Accepted 3 December 2018.

It has been suggested that some microorganisms, including plant growth-promoting rhizobacteria, manipulate the level of ethylene in plants by degrading 1-aminocyclopropane-1carboxylic acid (ACC), an ethylene precursor, into $\alpha$-ketobutyrate and ammonia, using ACC deaminase (ACCd). Here, we investigated whether ACCd of Verticillium dahliae, a soil-borne fungal pathogen of many important crops, is involved in causing vascular wilt disease. Overexpression of the $V$. dahliae gene encoding this enzyme, labeled as $A C C d$, significantly increased virulence in both tomato and eggplant, while disruption of $A C C d$ reduced virulence. Both types of mutant produced more ethylene than a wild-type (70V-WT) strain, although they significantly differed in ACC content. Overexpression strains lowered ACC levels in the roots of infected plants, while the amount of $\mathrm{ACC}$ in the roots of plants infected with deletion mutants increased. To test the hypothesis that ACC acts as a signal for controlling defense, roots of WT and Never-ripe (Nr) tomato plants were treated with ACC before $V$. dahliae inoculation. Plants pretreated with ACC displayed less severe symptoms than untreated controls. Collectively, our results suggest a novel role of ACC as a regulator of both plant defense and pathogen virulence.

Verticillium dahliae is a soil-borne fungal pathogen that causes Verticillium wilt disease in a wide variety of economically important annual herbaceous, perennial, and woody plants

${ }^{\dagger}$ Corresponding author: M.-D. Tsolakidou; maria.tsolakidou@cut.ac.cy

Funding: This work was supported by the Cyprus University of Technology Dimitris Tsaltas Startup Grant EX064 2011-2014, Research Activities Fund, and Researcher's Fund and by funds from the State Scholarships Foundation of Greece (grant 2012-ПE2-3339) via the Operational Program "Education and Lifelong Learning" of the European Social Fund (ESF) within the National Strategic Reference Framework (2007-2013) with a Ph.D. scholarship awarded to Maria-Dimitra Tsolakidou.

*The $\boldsymbol{e}$-Xtra logo stands for "electronic extra" and indicates that six supplementary figures are published online.

(c) 2019 The American Phytopathological Society
(Bhat and Subbarao 1999; Fradin and Thomma 2006; Keykhasaber et al. 2017). Due to the broad host range, the ability to survive many years as microsclerotia in the soil and very limited control options, $V$. dahliae continuously causes severe crop losses in many temperate and subtropical regions around the world (Fradin and Thomma 2006; Robison et al. 2001; Tjamos 1989). V. dahliae evolved various mechanisms to overcome plant defense systems and facilitate in planta proliferation (Klosterman et al. 2009; Maruthachalam et al. 2011). Secretion of a variety of molecules, including cell wall-degrading enzymes, phytotoxins, and effectors, is one such mechanism (Luo et al. 2014; Tzima et al. 2011). Some regulatory proteins that control signal transduction pathways, such as GTP-binding proteins, mitogen-activated protein kinases, and protein kinase A, also play critical roles in virulence (Tzima et al. 2010, 2012).

Ethylene is a gaseous plant hormone that affects developmental processes such as flowering, senescence, fruit ripening, and leaf abscission and also participates in regulating responses to biotic and abiotic stresses (Abeles et al. 1992; Johnson and Ecker 1998). Certain bacteria and fungi also produce ethylene, presumably to manipulate plant ethylenemediated regulation of these processes in ways that facilitate their colonization of plants. Potential roles of pathogenproduced ethylene in virulence and disease development have been studied in $V$. dahliae and a few other pathogens (Al-Masri et al. 2006; Cristescu et al. 2002; Tzeng and Devay 1985; Tzima et al. 2010, 2012; Zhu et al. 2012, 2017). Ethylene may be involved in causing Verticillium wilt symptoms such as epinasty, stunting, premature senescence, and leaf abscission (Cronshaw and Pegg 1976; Wiese and Devay 1970). Ethylene perception is required for spore germination and appressorium formation in Colletotrichum gloeosporioides (Kim et al. 2000). In Botrytis cinerea, ethylene affected transcriptional reprogramming of the genes that may be involved in plant interaction (Chagué et al. 2006). However, its role in plant infection remains unclear (Chagué et al. 2002).

In plants, ethylene is synthesized from methionine through two intermediates, $S$-adenosyl-methionine ( $S$-AdoMet) and 1aminocyclopropane-1-carboxylic acid (ACC) (Adams and Yang 1979). In microorganisms, ethylene biosynthesis can occur via three pathways, one of which is the pathway 
employed by plants (Jia et al. 1999). Another pathway involves a multifunctional enzyme called ethylene-forming enzyme (EFE), which converts 2-oxoglutarate (OXO) to ethylene (Chagué 2010; Fukuda et al. 1986; Hottiger and Boller 1991). Ethylene can also be produced through oxidation of $\alpha$-keto$\gamma$-methylthiobutyric acid (KMBA), a substrate synthesized through deamination of methionine (Chagué et al. 2002; Cristescu et al. 2002; Primrose 1977). Tzeng and De Vay (1984) showed that two $V$. dahliae isolates from cotton could produce ethylene via the KMBA pathway and that addition of ACC to culture medium inhibited ethylene production. The genome of $V$. dahliae contains genes encoding ACC synthase (ACS), ACC deaminase (ACCd), and EFE. However, their role in pathogenicity and ethylene biosynthesis has not been elucidated. Many plant growth-promoting rhizobacteria (PGPR) that produce ACCd, which cleaves ACC into $\alpha$-ketobutyrate and ammonia, promote plant growth, presumably by lowering plant ethylene levels (Glick 2014; Honma and Shimomura 1978). Vanderstraeten and Van Der Straeten (2017) stated that the secretion of ACC from plant roots into the rhizosphere to attract and interact with PGPR suggests an ethylene-independent function for ACC. Several other studies also supported a model that ACC functions as a signal molecule (Tsang et al. 2011; Tsuchisaka et al. 2009; Van de Poel and Van Der Straeten 2014; $\mathrm{Xu}$ et al. 2008; Yoon and Kieber 2013).

Here, we investigated if and how ACCd affects the pathogenicity of $V$. dahliae and its growth, development, and ethylene production, by disrupting the gene encoding this enzyme, entitled $A C C d$, and also by overexpressing it. We also investigated the role of ACC in disease development and whether plant response to ACC could be ethylene-independent by evaluating how WT and $\mathrm{Nr}$ (ethylene-insensitive) tomato plants pretreated with ACC respond to infection by $V$. dahliae.

\section{RESULTS}

Overexpression and disruption of the $A C C d$ gene.

The $V$. dahliae ACCd gene consists of an open reading frame (ORF) of 1,038 bp, which is interrupted by one intron of $90 \mathrm{bp}$ located at position 186, and encodes a protein of 345 amino acids. Its ORF fused to the Magnaporthe oryzae ribosomal protein promoter, a strong constitutive promoter, was introduced into strain $70 \mathrm{~V}-\mathrm{WT}$, a race 1 isolate from tomato (Pantelides et al. 2010), to increase its expression (Supplementary Fig. S1). Based on the amount of $A C C d$ transcripts in 12 transformants, three transformants (Vd6ADM1, Vd6ADM2, and $V d 6 A D M 10$ ), which produced up to 12 times more transcripts than 70V-WT, were chosen for subsequent experiments. The gene was also deleted (Supplementary Fig. S2). ACCd transcripts were absent in deletion mutants $70 \triangle A D 1.4$ and 70 $\triangle A D 3.4$. A functional copy of $A C C d$ was introduced into $70 \triangle A D 1.4$ for complementation, resulting in $70 C A D 1.2 .2$. The amount of $A C C d$ transcripts in 70CAD1.2.2 was comparable to that in $70 \mathrm{~V}-\mathrm{WT}$.

\section{Effect of both mutations on growth, microsclerotia} formation, and conidial production and germination.

$70 \mathrm{~V}-\mathrm{WT}$ and its mutants were cultured on minimal medium to investigate the role of $A C C d$ in growth and development. Their colony sizes were similar (Fig. 1A), however, compared
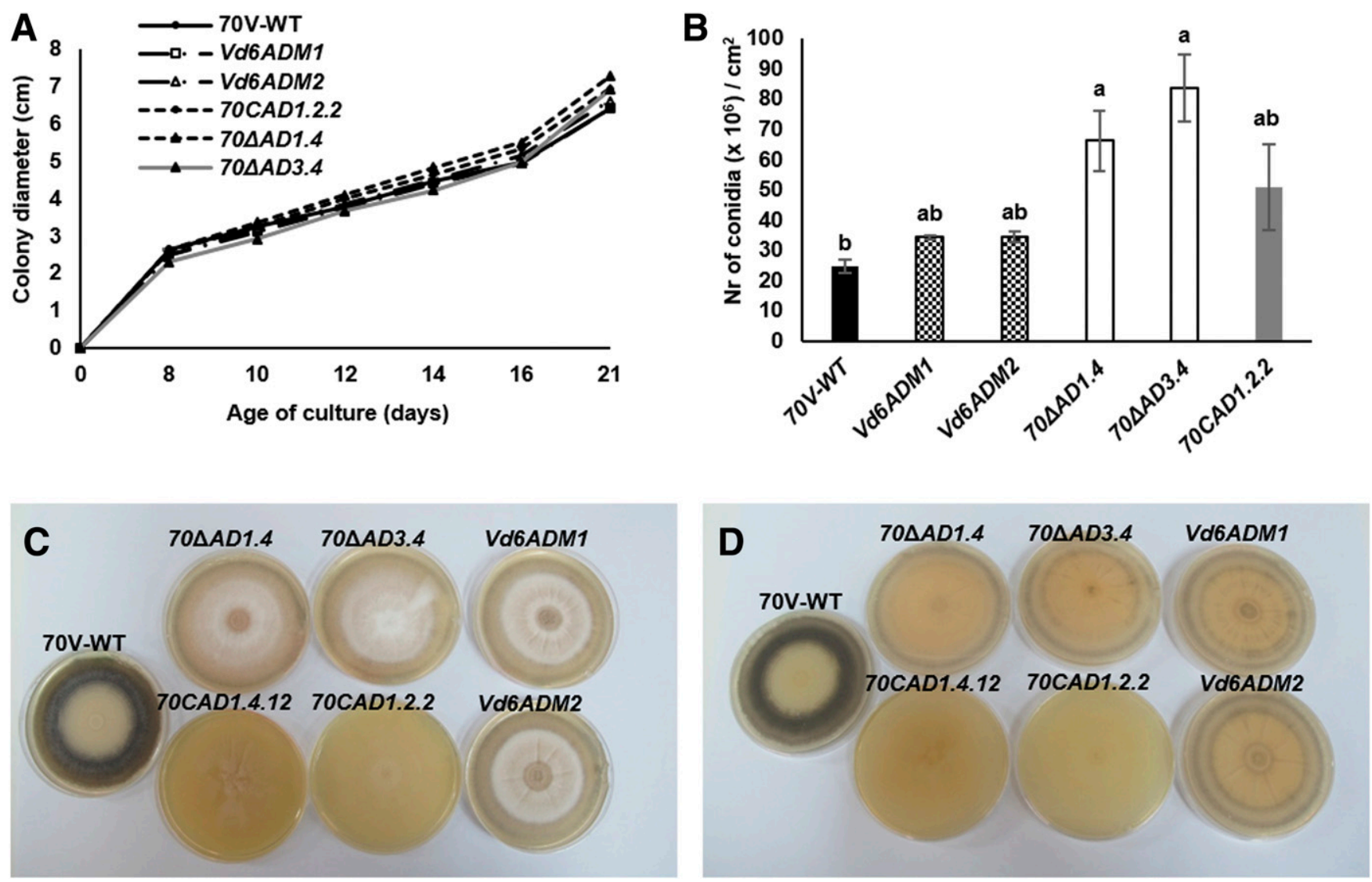

Fig. 1. Colony growth, microsclerotia formation and spore production of 70V-WT and 1-aminocyclopropane-1-carboxylic acid deaminase (ACCd) mutants. A, Colony growth of 70V-WT, $A C C d$ deletion mutants (70 $A A D 1.4$ and $70 \triangle A D 3.4)$, overexpression strains (Vd6ADM1 and Vd6ADM2), and complemented deletion mutant 70CAD1.2.2 over time and $\mathbf{B}$, their spore production on potato dextrose agar. Vertical bars indicate the standard errors of five and three replicates, respectively. Different letters in B note statistically significant differences according to Tukey's multiple range test at $P \leq 0.05$. C and $\mathbf{D}$, Colony appearances from, respectively, the top and bottom of representative plates 30 days after inoculation. 
with 70V-WT, which formed abundant darkly pigmented microsclerotia, both types of mutants produced fewer microsclerotia but more aerial hyphae (Fig. 1C and D). When cultured on potato dextrose agar (PDA), deletion mutants $70 \triangle A D 1.4$ and $70 \triangle A D 3.4$ produced significantly more conidia than $70 \mathrm{~V}$ WT (Fig. 1B), but no significant difference was noted in liquid sucrose sodium nitrate (SSN) medium (Supplementary Fig. S3). However, on PDA amended with 10 or $100 \mu \mathrm{M}$ ACC, significantly reduced conidial production was observed in $70 \triangle A D 3.4$ (Fig. 2B). Conidial production by overexpression strains Vd6ADM1 and Vd6ADM2 and complemented deletion mutant 70CAD1.2.2 was comparable to 70V-WT when cultured on PDA (Fig. 1B), in SSN, and on PDA supplemented with ACC (Fig. 2B). ACC at $500 \mu \mathrm{M}$ inhibited colony growth of $70 \mathrm{~V}-\mathrm{WT}$, Vd6ADM1, and 70CAD1.2.2 (Fig. 2A). Spore germination was similar among all strains.

\section{Involvement of $A C C d$ in pathogenesis.}

Virulence of deletion mutants and overexpression strains in tomato and eggplant was evaluated. Infection of tomato plants was performed in both a growth room and greenhouse. Compared with 70V-WT, two deletion mutants caused significantly less disease, whereas plants infected with two overexpression strains displayed more severe wilting symptoms (Fig. 3A). Tomato plants inoculated with 70V-WT and overexpression strains Vd6ADM1 and Vd6ADM2 exhibited the first wilting symptoms at 8 days postinoculation (dpi). At $14 \mathrm{dpi}$, the disease severity caused by $V d 6 A D M 1$ and $V d 6 A D M 2$ reached 50 and $42 \%$, respectively, while that caused by $70 \mathrm{~V}-\mathrm{WT}$ reached $25 \%$. Plants inoculated with deletion mutants $70 \triangle A D 1.4$ and $70 \triangle A D 3.4$ displayed only mild chlorosis in older leaves at 14 dpi, with disease severity being 12 and $12.5 \%$, respectively (Fig. 3B). Consistent with the onset and severity of symptom development, relative area under the disease progress curve (AUDPC) values showed that $70 \triangle A D 1.4$ and $70 \triangle A D 3.4(7 \%)$ caused significantly less disease than 70V-WT (13.9\%), complemented deletion mutant 70CAD1.2.2 (10.3\%), and overexpression strains Vd6ADM1 and Vd6ADM2 (31.3 and 26.4\%, respectively) (Fig. 3C). Compared with plants inoculated with $70 \mathrm{~V}-\mathrm{WT}$, average heights and fresh weights of plants inoculated with $70 \triangle A D 1.4$ and $70 \triangle A D 3.4$ were higher, while those of plants inoculated with $V d 6 A D M 1$ and $V d 6 A D M 2$ were significantly lower (Figs. 3D and E). Although the difference between 70V-WT and two overexpression strains was less pronounced in greenhouse evaluations, similar patterns were observed (Supplementary Fig. S4). Relative AUDPC values after infection by Vd6ADM1 and Vd6ADM2 were 17 and $20 \%$,

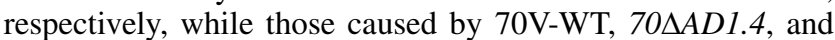
$70 \triangle A D 3.4$ were $13.6,7.6$, and $9.8 \%$, respectively.

Fungal biomass in the vascular tissues of infected plants was assessed, using quantitative polymerase chain reaction (qPCR), to determine whether it correlates with disease severity. At 8 dpi, fungal DNA was detectable in all treatments. However, the amount of fungal DNA in plants infected with Vd6ADM1 and $V d 6 A D M 2$ was significantly higher than that in plants infected with 70V-WT (Fig. 4A). The amount of DNA for deletion mutants $70 \triangle A D 1.4$ and $70 \triangle A D 3.4$ was similar to that of $70 \mathrm{~V}$ WT (Fig. 4A). At $21 \mathrm{dpi}$, the amount of DNA for Vd6ADM1 and $V d 6 A D M 2$ was 20- and 11-fold higher than that of $70 \mathrm{~V}$ WT. However, the difference between 70V-WT and deletion mutants was not significant (Fig. 4B).

In eggplant inoculated with three overexpression strains, disease progression was more rapid (Fig. 5A). At 14 dpi, about $60 \%$ of the leaves of plants infected with Vd6ADM1, $V d 6 A D M 2$, and $V d 6 A D M 10$ displayed wilt symptoms, while approximately $50 \%$ of the leaves showed wilt symptoms in plants infected with 70V-WT (Fig. 5B). Relative AUDPC values were consistent with higher virulence of $V d 6 A D M 1$, Vd6ADM2, and $\operatorname{Vd} 6 A D M 10(35,33$, and $37 \%$, respectively) than that of $70 \mathrm{~V}-\mathrm{WT}$ (23\%) (Fig. 5C). Similar to tomato, eggplant infected with deletion mutants showed less chlorosis and wilting symptoms (Fig. 6A) with disease severity at 13 dpi being 40 and $33 \%$, respectively compared with $60 \%$ caused by 70V-WT (Fig. 6B). Relative AUDPC values after infection by $70 \triangle A D 1.4$ and $70 \triangle A D 3.4$ were 23 and $19 \%$, respectively, while that of 70V-WT was 33\% (Fig. 6C).

\section{Both mutations did not affect conidial adhesion to tomato roots and root surface colonization.}

To facilitate monitoring of conidial attachment to roots and early stages of root colonization, deletion mutants $70 \triangle A D 1.4$ and $70 \triangle A D 3.4$, overexpression strain $V d 6 A D M 1$, and 70V-WT were transformed to constitutively express a red fluorescent protein (AsRed), resulting in $70 \triangle A D 1.4 R, 70 \triangle A D 3.4 R$, $V d 6 A D M 1 R$, and 70V-WTR. At $1 \mathrm{dpi}$, conidia of all strains attached to the root surface similarly (Fig. 7A to D). At 5 dpi, no significant differences in spore attachment and root colonization were observed (Fig. 7E to H). Subsequently, disease severity in plants infected with these AsRed transformants was calculated. At $17 \mathrm{dpi}$, plants inoculated with $V d 6 A D M 1 R$ showed symptoms of wilting, necrosis, and leaf abscission, with disease severity of $18.5 \%$ (Fig. $8 \mathrm{~B}$ ). In contrast, 70VWTR, 70 $\triangle A D 1.4 R$, and $70 \triangle A D 3.4 R$ caused the disease severity of $11.5,4.3$, and $5.3 \%$, respectively (Fig. 8B). Relative
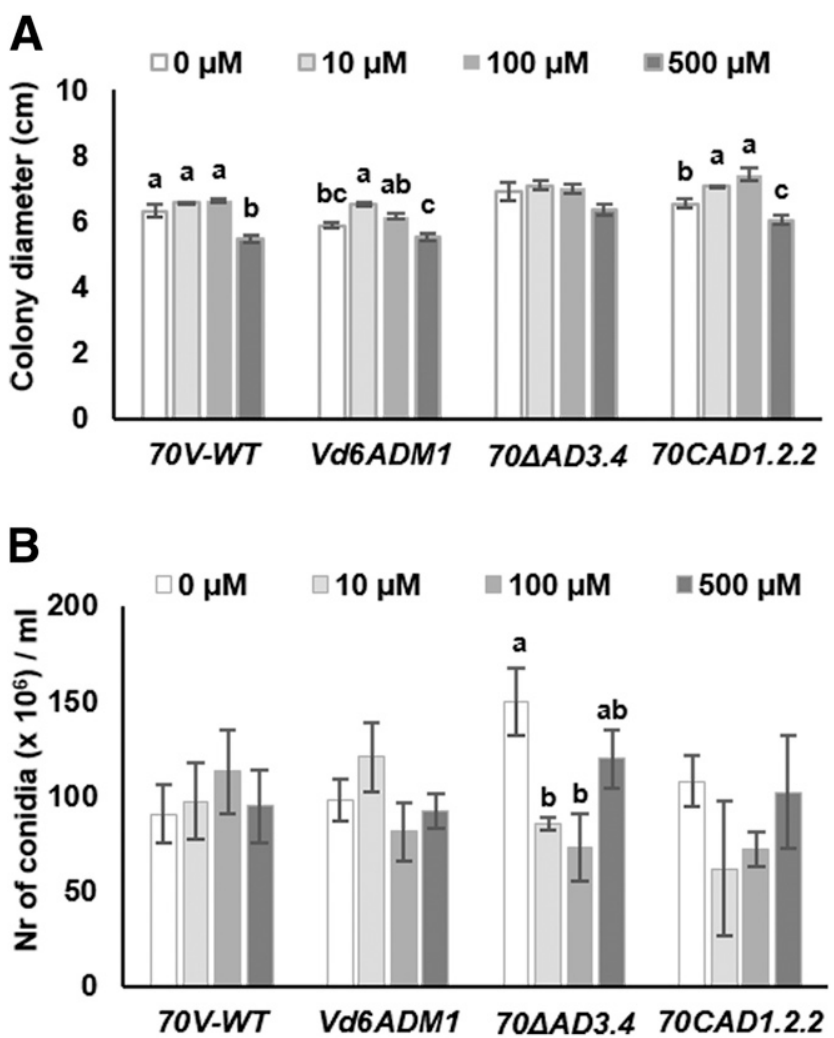

Fig. 2. A, Colony diameter and B, spore production of 70V-WT and 1aminocyclopropane-1-carboxylic acid deaminase $(A C C d)$ mutants in the presence of ACC. 70V-WT, deletion mutant 70 $\triangle A D 3.4$, overexpression strain $V d 6 A D M 1$, and complemented deletion mutant $70 C A D 1.2 .2$ were cultured on potato dextrose agar supplemented with $0,10,100$, or $500 \mu \mathrm{M}$ ACC. Vertical bars indicate the calculated standard errors of five (A) and three $(\mathrm{B})$ replicates. All values were subjected to analysis of variance. For data that showed a significance level of $P \leq 0.05$, Tukey's post hoc analysis was also performed. 
AUDPC values confirmed the lower virulence of $70 \triangle A D 1.4 R$ and $70 \triangle A D 3.4 R(0.7$ and $0.9 \%)$ and the higher virulence of $\operatorname{Vd} 6 A D M 1 R(6.1 \%)$ compared with 70V-WTR $(3.5 \%)$ (Fig. 8C).

A

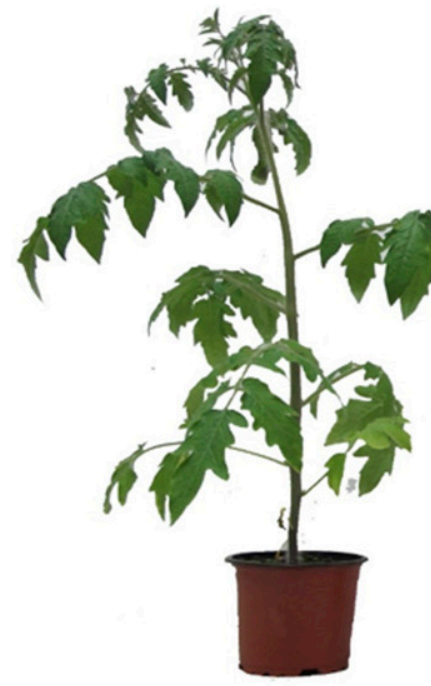

Control
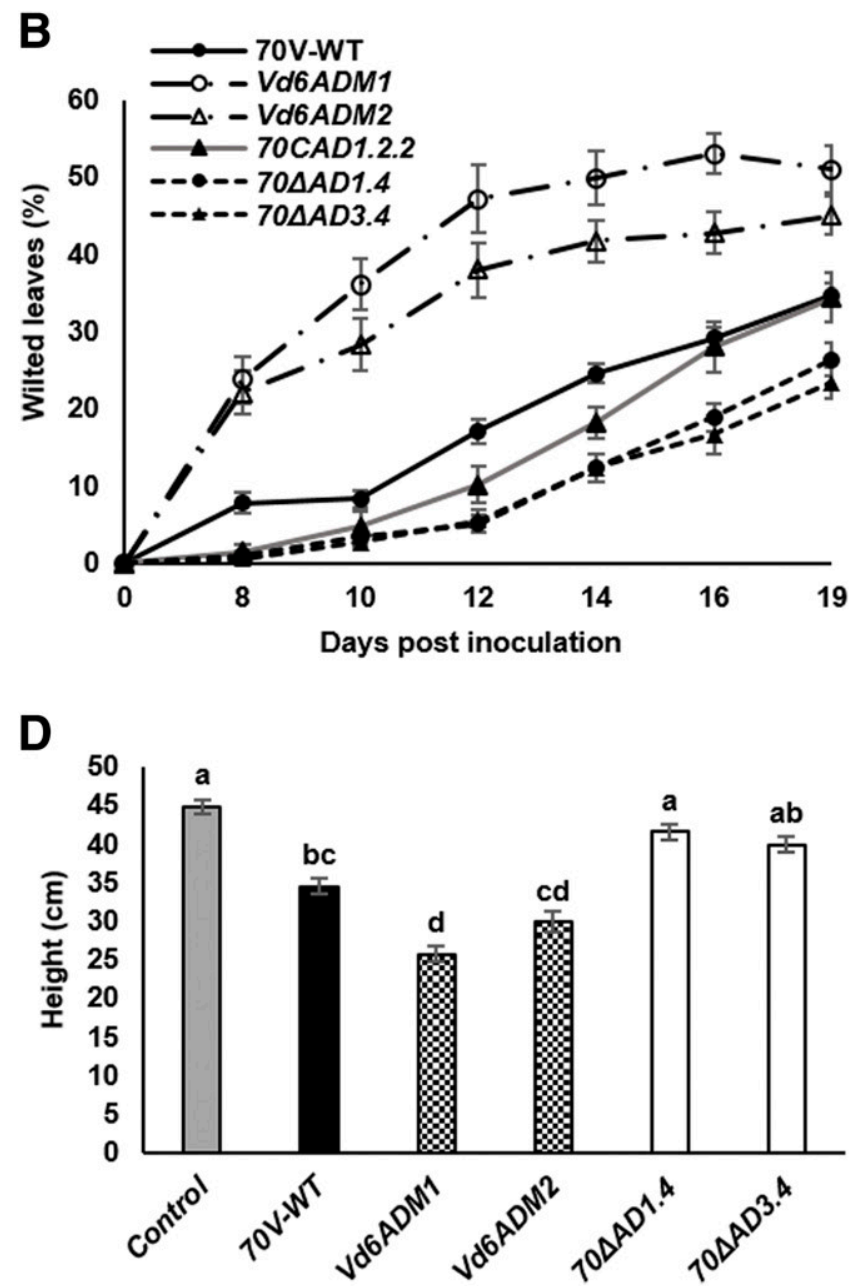

Both mutations affected ethylene production.

Since ACC is the precursor for ethylene in the methionineACC biosynthetic pathway, we hypothesized that ACCd deletion and overexpression would affect ethylene production.

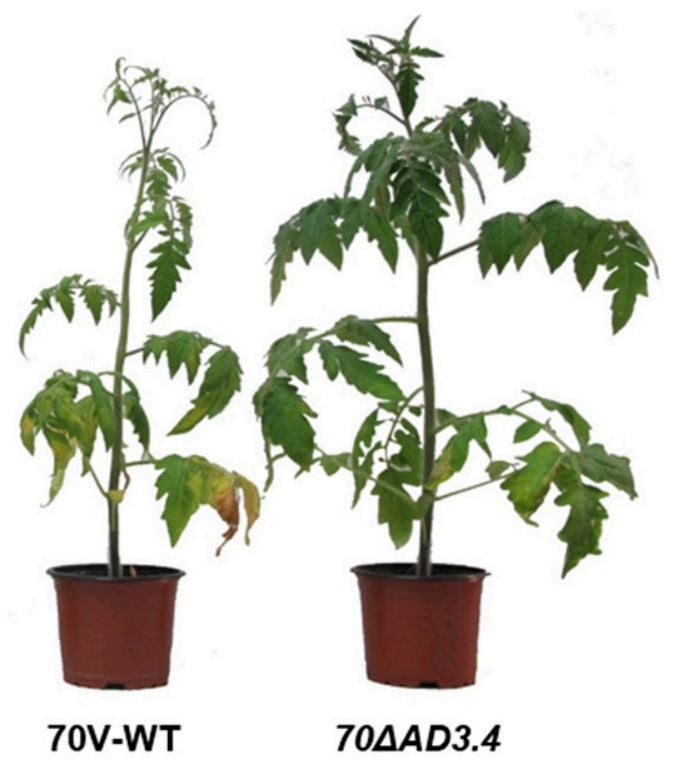

C

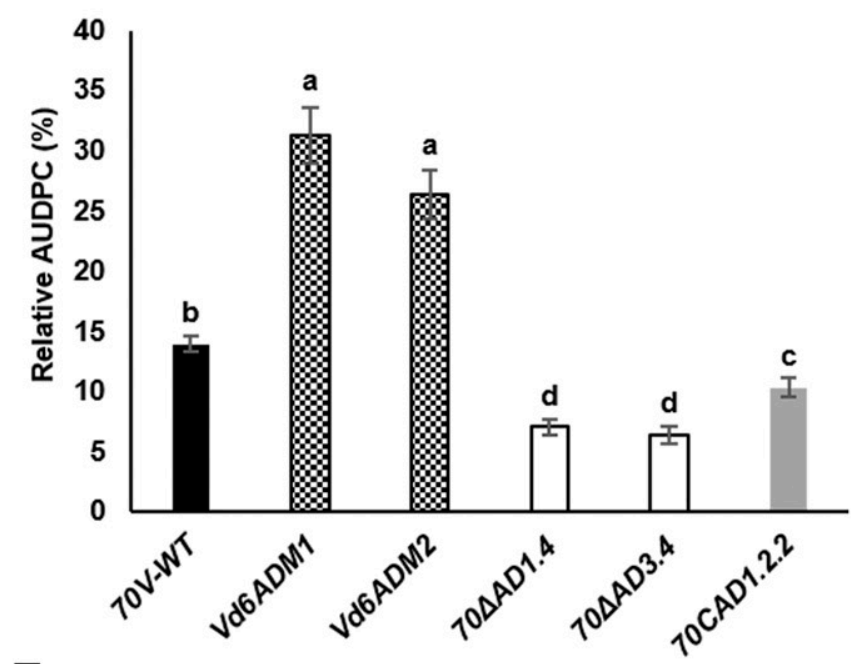

E

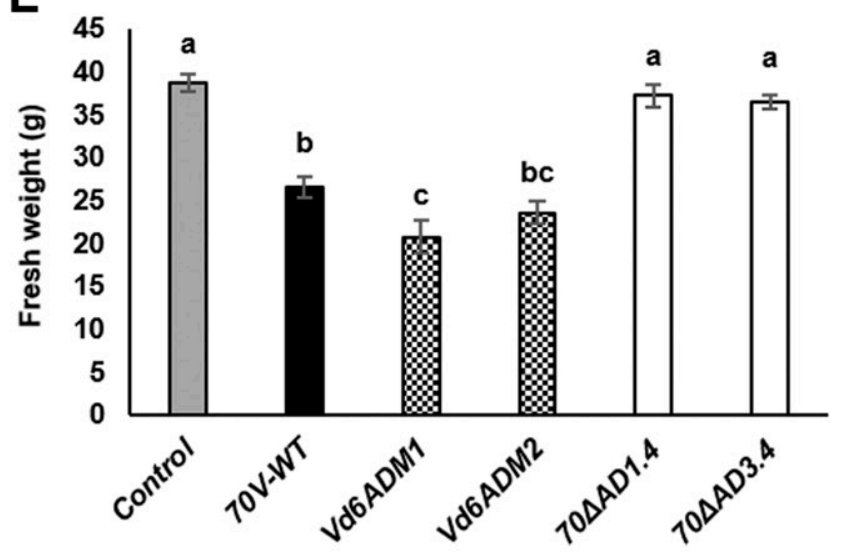

Fig. 3. Disease severity of tomato plants infected with 70V-WT and 1-aminocyclopropane-1-carboxylic acid deaminase (ACCd) mutants. Tomato plants were

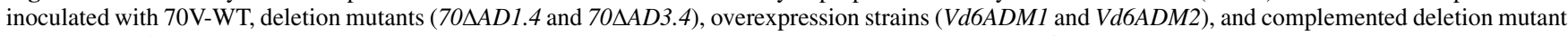
70CAD1.2.2. A, Representative tomato plants at 19 days after inoculation. B, Disease progress over time, C, amount of disease expressed as relative area under the disease progress curve, $\mathbf{D}$, height, and $\mathbf{E}$, fresh weight of plants. Vertical bars indicate the standard errors based on 24 replicates. All values were subjected to analysis of variance. Different letters in C, D, and E note statistically significant differences according to Tukey's multiple range test at $P \leq 0.05$. 
Ethylene production by $70 \mathrm{~V}-\mathrm{WT}$ and its mutants fluctuated during 14 days of cultivation (Fig. 9A). The amount of ethylene produced by $70 \triangle A D 3.4$ was higher than that of $70 \mathrm{~V}-\mathrm{WT}$ at multiple timepoints, with the maximum difference being observed at day 12. Interestingly, the amount of ethylene produced by $V d 6 A D M 1$ was also higher than that by $70 \mathrm{~V}-\mathrm{WT}$ at days 4,8 , and 12, but at days 6 and 14, no significant difference was observed (Fig. 9A).

Expression patterns of $A C S$ and $E F E$ were determined to investigate whether both mutations affect the expression of other genes involved in ethylene production. The amount of ACS transcripts in $70 \triangle A D 3.4$ and $V d 6 A D M 1$ appeared lower than that in 70V-WT at day 4, but at days 6, 8, and 12, they looked similar (Fig. 9B). The amount of EFE transcripts was highest at day 4 in all three strains and subsequently decreased. However, no significant differences among the strains were observed at all timepoints (Fig. 9C). We also checked the production of KMBA, another substrate for ethylene, in 70V-WT and mutants. All strains produced KMBA as evidenced by the formation of a yellow precipitate, an indicator for KMBA presence (Supplementary Fig. S5) (Chagué et al. 2002; Primrose 1977).

\section{$A C C d$ manipulations altered fungal and plant ACC content.}

Consistent with the role of ACCd in cleaving ACC, after 7 days of culture, ACC concentration in overexpression strains $V d 6 A D M 1$ and $V d 6 A D M 2$ was significantly lower than that in $70 \mathrm{~V}-\mathrm{WT}$, and ACC levels in deletion mutants $70 \triangle A D 1.4$ and $70 \triangle A D 3.4$ were higher than that in 70V-WT (Fig. 10A).

To investigate if $A C C d$ manipulations in $V$. dahliae could affect $\mathrm{ACC}$ production in tomato plants, the ACC content in the roots and shoots of infected plants was analyzed at 2 and 4 dpi. The ACC content in roots of plants infected with Vd6ADM1 and $V d 6 A D M 2$ were significantly lower than those in plants infected with 70V-WT and the mock-inoculated controls at both timepoints (Fig. 10B). At 2 dpi, the ACC content in roots of plants infected with $70 \triangle A D 1.4$ and $70 \triangle A D 3.4$ deletion mutants was not significantly different from those observed in 70V-WT and mock-inoculated plants (Fig. 10B). However, at 4 dpi, root ACC levels in 70V-WT and mock-inoculated controls were reduced, while those in $70 \triangle A D 1.4$ and $70 \triangle A D 3.4$ infected plants remained unchanged (Fig. 10B). The ACC content in the shoots of infected plants was also measured at 2 and 4 dpi and showed no significant differences among all treatments (Fig. $10 \mathrm{C})$. ACC was also measured in plants root-drenched with ACC and the amount of ACC in both the roots and shoots of ACC-treated plants was found to be significantly greater compared with the mock-inoculated controls (Supplementary Fig. S6).

\section{Exogenous application of ACC before infection reduced disease symptoms in tomato plants.}

To determine whether ACC affects disease development, roots of WT and $N r$, a mutant insensitive to ethylene, tomato plants were treated with ACC prior to infection with 70V-WT. After ACC treatment, both plants displayed reduced symptoms and slower disease progression compared with untreated plants (Fig. 11A). At $16 \mathrm{dpi}$, about $23 \%$ of the leaves in untreated plants displayed wilt symptoms, while only 10 and $8 \%$, respectively, of the leaves in ACC treated WT and $\mathrm{Nr}$ plants showed symptoms (Fig. 11B). The relative AUDPC analysis showed similar trends (Fig. 11C).

\section{DISCUSSION}

Ethylene performs diverse regulatory functions in plants (Abeles et al. 1992; Johnson and Ecker 1998). Besides its role in regulating plant development and plant defense responses to abiotic or biotic stresses, ethylene may be employed as a virulence factor by plant pathogens (Abeles et al. 1992; van Loon et al. 2006). Effect of exogenously applied ethylene on virulence and disease development by diverse pathogens compelled inquiries into whether ethylene produced by microbes affect their interaction with plants (Chagué et al. 2006; Cristescu et al. 2002; Cronshaw and Pegg 1976; Marco and Levy 1979; Tzeng and Devay 1985; Weingart et al. 2001). Tzeng and DeVay (1984) reported that two V. dahliae isolates from cotton produced ethylene via the KMBA pathway. Nondefoliating isolate SS4 produced more ethylene than T9, a defoliating isolate, in vitro, but cotton plants inoculated with T9 produced more ethylene than those inoculated with SS4 (Tzeng and DeVay 1984; Wiese and Devay 1970). Since the source of ethylene in infected plants was unknown, it was not clear about whether ethylene produced by $V$. dahliae contributed to virulence. Here, we manipulated the $A C C d$ gene of $V$. dahliae in two ways to investigate its role in growth, development, pathogenesis, and ethylene production. Both mutations

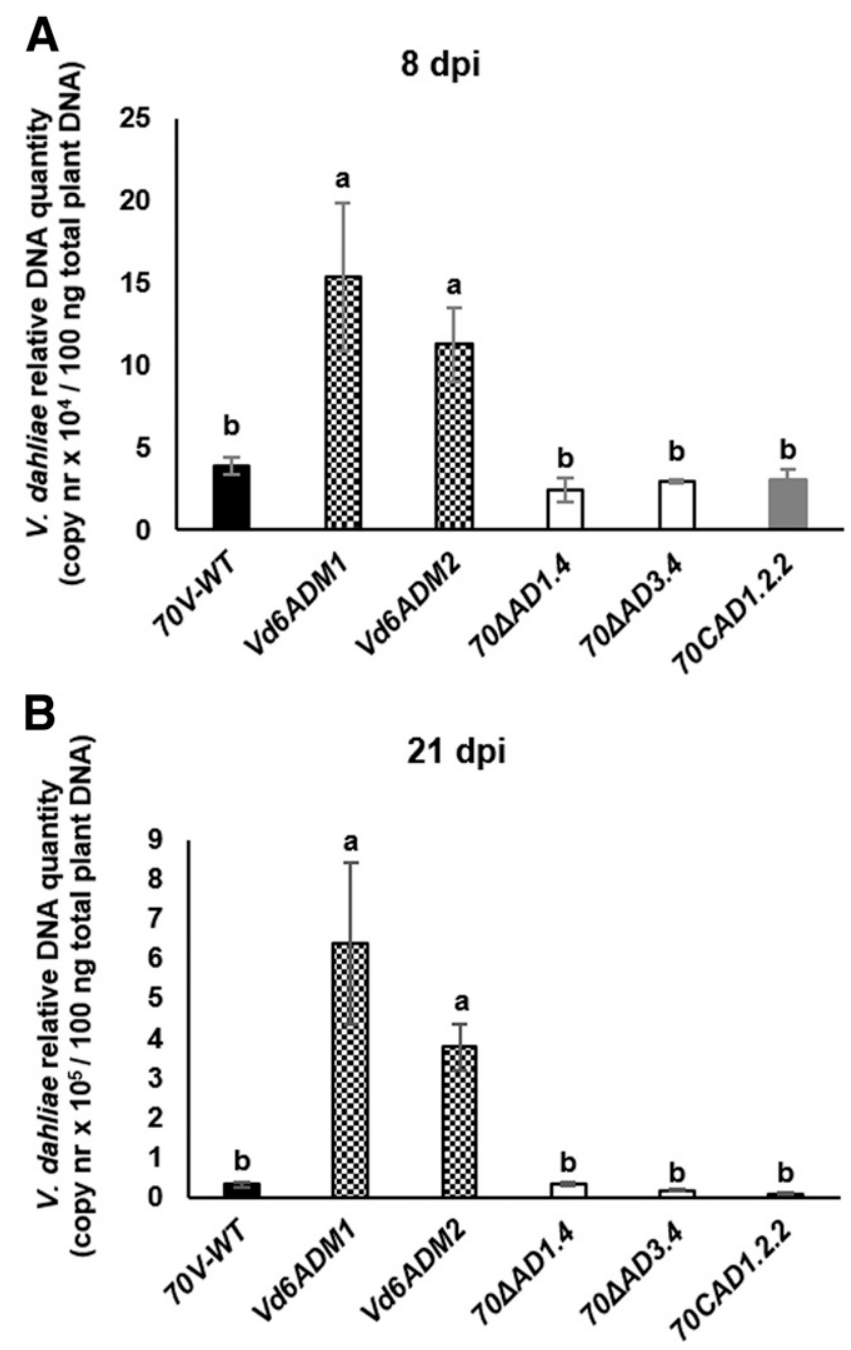

Fig. 4. Quantification of fungal biomass in infected plants. A, The amount of fungal DNA in the stem of tomato plants was quantified at 8 and $\mathbf{B}, 21$ days after inoculation with 70V-WT, deletion mutants $(70 \triangle A D 1.4$ and $70 \triangle A D 3.4)$, overexpression strains (Vd6ADM1 and Vd6ADM2), and complemented deletion mutant 70CAD1.2.2. Vertical bars indicate the calculated standard errors of three replicates (pool of three plants per replicate per treatment). Columns with different letters were statistically significantly different according to Tukey's multiple range test at $P \leq 0.05$. 
did not significantly affect colony growth, spore production (cultured in SSN), and spore germination (Fig. 1) but suggested the involvement of the gene and ACC in determining disease severity.

The ACC-dependent pathway may only play a minor role in ethylene synthesis in $V$. dahliae.

In phytopathogenic fungi such as Penicillium digitatum and Fusarium oxysporum, more than one ethylene biosynthetic pathway exists (Billington et al. 1979; Chagué 2010; Fukuda et al. 1986; Hottiger and Boller 1991; Jia et al. 1999). The production of KMBA and the presence of genes encoding enzymes involved in the ACC and 2-OXO dependent ethylene biosynthesis pathways in $V$. dahliae suggested the participation of multiple pathways in synthesizing ethylene. Since ACCd cleaves ACC into $\alpha$-ketobutyrate and ammonia (Honma and Shimomura 1978), we hypothesized that if the ACC-dependent pathway mainly produces ethylene, overexpression of $A C C d$ would lead to decreased ethylene production while its deletion would increase production. Although the amount of ethylene produced by deletion mutants was higher than that by overexpression strains at most timepoints, both mutants produced more ethylene than did 70V-WT (Fig. 9). This result does not support the hypothesis and, instead, suggests that ACC, $\alpha$-ketobutyrate, ammonia, or combinations of these metabolites might affect the production of ethylene via other pathways. Transcript levels of the ACS and EFE genes in 70V-WT, overexpression strain $V d 6 A D M 1$, and deletion mutant $70 \triangle A D 3.4$ were not significantly different, with the exception of the $A C S$ gene at one timepoint (Fig. 9), suggesting that the effect does not occur at the gene-expression level.

\section{Manipulation of the $A C C d$ gene affects}

the virulence of $V$. dahliae.

ACCd has been shown to affect plant health in different ways, depending on where it is expressed. Glick et al. (1998) suggested that some ACC produced by plants is released through roots and is metabolized by ACCd of root colonizing bacteria into $\alpha$-ketobutyrate and ammonia, potentially lowering the amount of ethylene produced by plants. Several studies have shown that plants inoculated with PGPR strains expressing this enzyme formed longer roots and shoots and became more resistant to a variety of abiotic stresses, including flooding, drought, contamination by heavy metals, and salinity (Cheng et al. 2007; Glick 2014; Grichko et al. 2000; Mayak et al. 2004; Penrose and Glick 2003; Saleem et al. 2007), and exhibited increased resistance against pathogenic nematodes, bacteria, fungi, and oomycetes (Husen et al. 2011; Nascimento

A
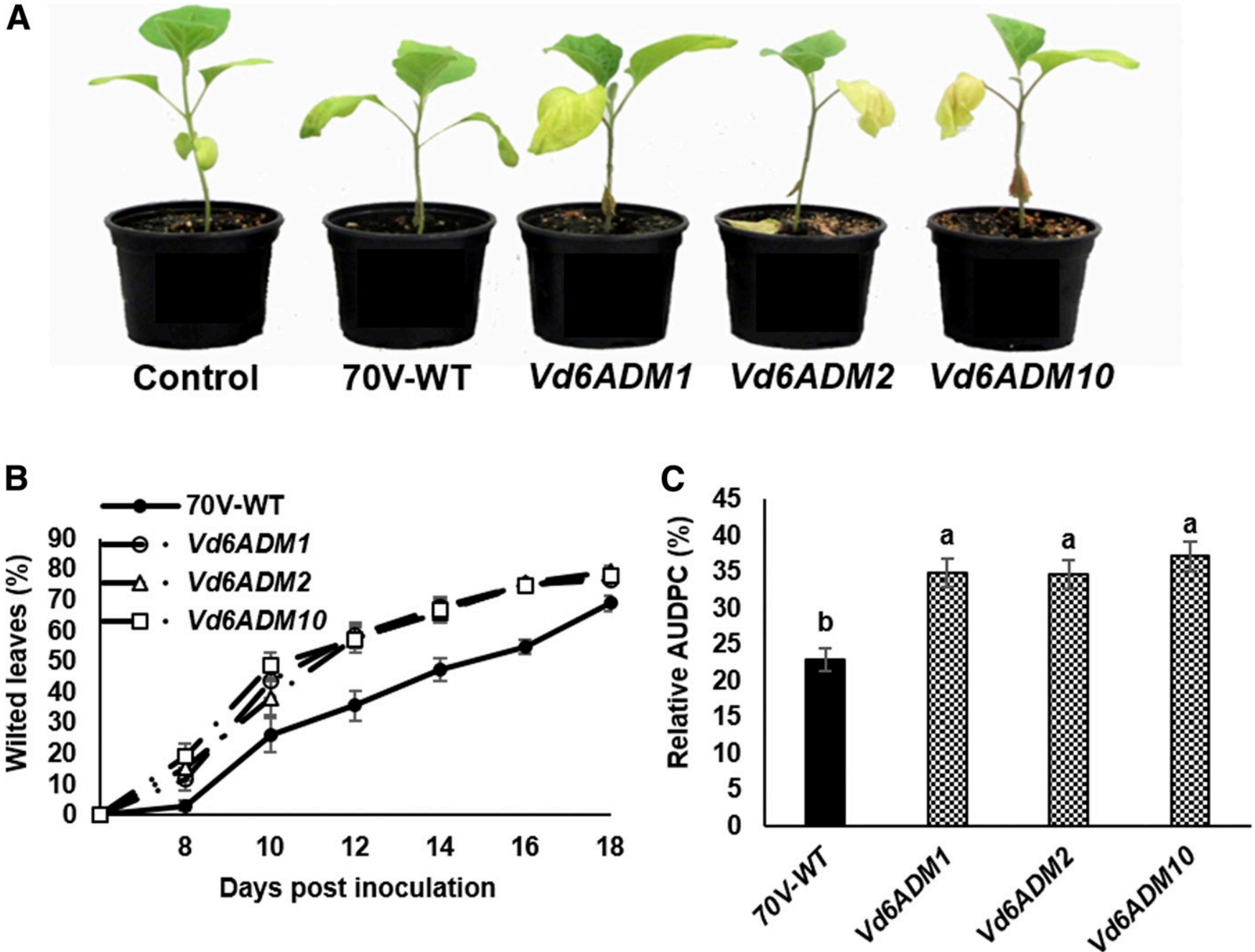

Fig. 5. Disease symptoms in eggplant infected with 70V-WT and 1-aminocyclopropane-1-carboxylic acid deaminase (ACCd) overexpression strains. Eggplant was infected with 70V-WT and three overexpression strains. A, Symptoms at 14 days after inoculation, B, disease progression over time, and C, relative area under the disease progress curve. Vertical bars indicate the standard errors based on 20 replicates. All values were subjected to analysis of variance. Different letters in $\mathrm{C}$ note statistically significant differences according to Tukey's multiple range test at $P \leq 0.05$. 
et al. 2013; Toklikishvili et al. 2010). For example, Pseudomonas fluorescens CHA0 transformed with ACCd of Pseudomonas putida UW4 caused enhanced protection of cucumber from Pythium spp. and potato from Pectobacterium carotovorum subsp. carotovorum but failed to protect tomato from Fusarium oxysporum f. sp. radicis-lycopersici (Wang et al. 2000).

The ACCd gene is also present in some plant-pathogenic bacteria, but its role is not clearly understood (Nascimento et al. 2018). Pseudomonas brassicacearum expressing ACCd caused a wide range of effects on inoculated tomato plants, including growth promotion, neutral or increased disease severity depending on the number of bacterial cells inoculated and environmental conditions (Belimov et al. 2007). Introduction of a bacterial ACCd gene into Agrobacterium tumefaciens enhanced its virulence, increasing transformation frequency of several plant species (Nonaka and Ezura 2014). Exogenous application of ethylene and ACC caused reduced T-DNA transfer and transformation of melon and tomato (Davis et al. 1992; Ezura et al. 1999), suggesting the role of ACC as a negative regulator of virulence. However, whether ACCd or ACC affects virulence (vir) gene expression was not determined. Similarly to A. tumefaciens, overexpression of the endogenous ACCd gene in $V$. dahliae enhanced virulence in tomato and eggplant (Figs. 3 and 5). Overexpression strains, which contained lower levels of ACC than 70V-WT (Fig. 10A), colonized the vascular system of infected plants to a greater extent than 70V-WT (Fig. 4). In contrast, plants inoculated with deletion mutants $70 \triangle A D 1.4$ and $70 \triangle A D 3.4$, which produced higher levels of ACC than 70V-WT (Fig. 10A), showed significantly reduced symptoms than those infected with 70V-WT and overexpression strains (Figs. 3 and 6).

\section{Does ACC act as a potential regulator of virulence and plant defense?}

ACC seems to act as a potential negative regulator of virulence in $V$. dahliae but functions as a positive regulator of defense, which was suggested by three lines of evidence: i) $A C C d$ deletion mutants that had a higher ACC content than the wildtype strain (Fig. 10A) caused significantly less disease in tomato and eggplant (Figs. 3 and 6), ii) ACC content in roots of plants infected with $A C C d$ deletion mutants was higher than that in mock-inoculated and 70V-WT infected plants (Fig. 10B), and iii) ACC treatment of plants significantly reduced disease in both WT and $\mathrm{Nr}$ tomato plants (Fig. 11). It is also possible that the enhanced virulence of overexpression strains was caused by the increased degradation of the amount of plant ACC. Application of ACC to Arabidopsis thaliana plants resulted in enhanced resistance against Pseudomonas syringae pv. tomato (Pieterse et al. 1998, 2000; van Wees et al. 1999), also supporting the role of ACC as a positive regulator of defense. Other studies also suggested that ACC could be more
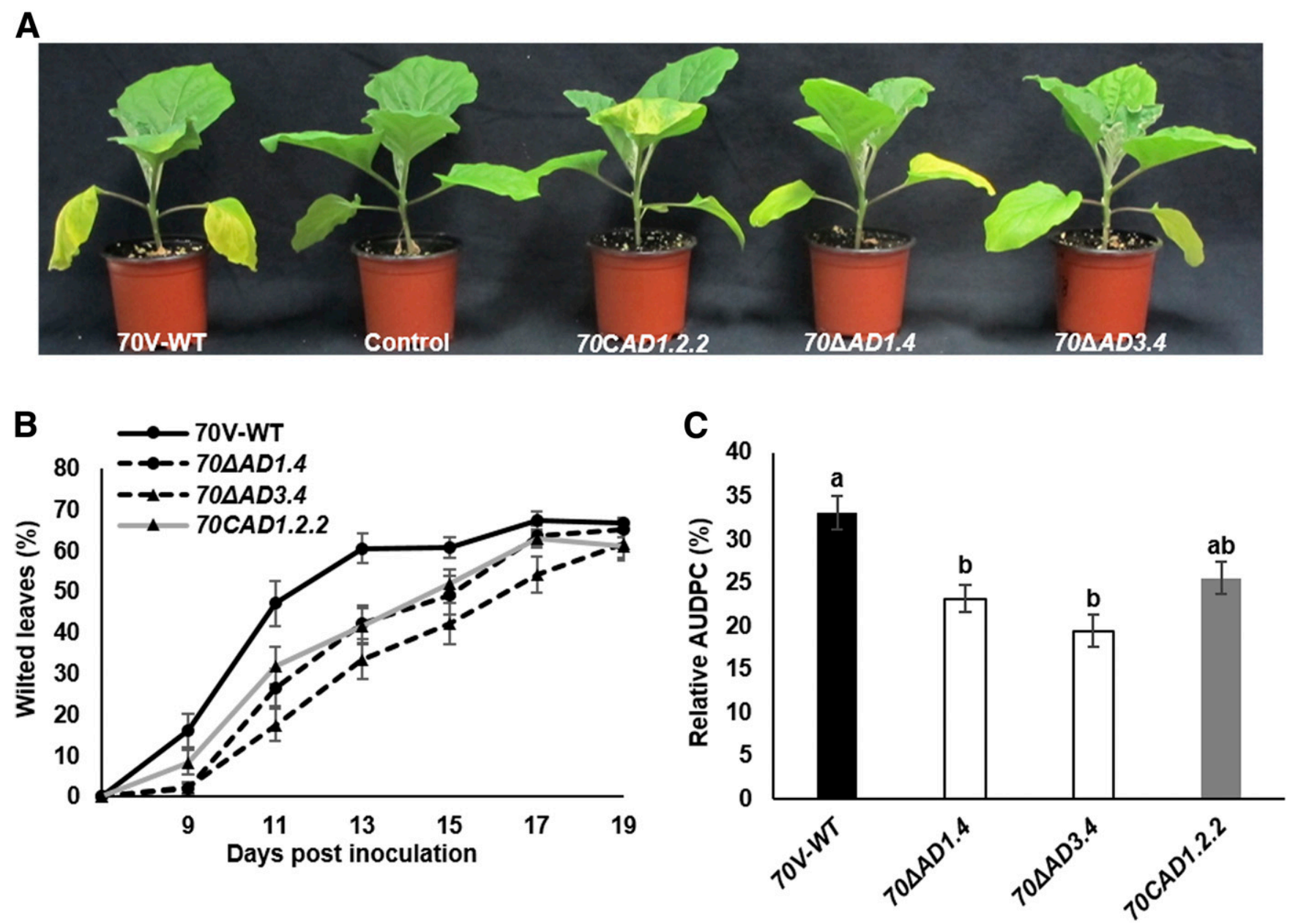

Fig. 6. Disease symptoms in eggplant infected with 70V-WT and 1-aminocyclopropane-1-carboxylic acid deaminase (ACCd) deletion mutants. Eggplant was

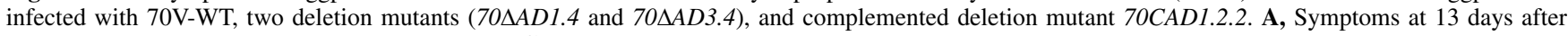
inoculation, $\mathbf{B}$, disease progression over time, and $\mathbf{C}$, relative area under the disease progress curve. Vertical bars indicate the standard errors based on 20 replicates. All values were subjected to analysis of variance. Different letters in C note statistically significant differences according to Tukey's multiple range test at $P \leq 0.05$. 
than just a precursor for ethylene but acts as a signaling molecule (Tsang et al. 2011; Tsuchisaka et al. 2009; Van de Poel and Van Der Straeten 2014; Xu et al. 2008; Yoon and Kieber 2013). Root cell elongation in Arabidopsis thaliana appears to be controlled by ACC, which is ethylene-independent (Tsang et al. 2011; Xu et al. 2008). ACC also plays a possible role in phytohormone crosstalk (Nascimento et al. 2018; Van de Poel and Van Der Straeten 2014).

The findings of the present study provide evidence for the role of the $A C C d$ gene in the pathogenicity of soil-borne fungus $V$. dahliae. Contrary to the plant growth-promoting function of ACCd conferred by PGPR, overexpression of the $A C C d$ gene in $V$. dahliae resulted in enhanced virulence, demonstrating a different role of this gene in phytopathogenic fungi. Given the fact that even subtle changes in the production of plant hormones can affect plant-microbe interactions differently, further investigation is needed into how ACC is produced on both the fungal and plant sides and how its changes influence the outcome of infection.

\section{MATERIALS AND METHODS}

\section{Fungal isolates and culture conditions.}

For long-term storage, 70V-WT and its transformants were preserved as a conidial suspension $\left(4 \times 10^{7}\right.$ conidia per milliliter) in $25 \%$ glycerol at $-80^{\circ} \mathrm{C}$. They were activated by culturing on PDA (Oxoid) for 5 days at $25^{\circ} \mathrm{C}$. Transformants were cultured on a medium supplemented with $50 \mu \mathrm{g}$ of geneticin (Life Technologies) or hygromycin B (Duchefa Biochemies) per milliliter.
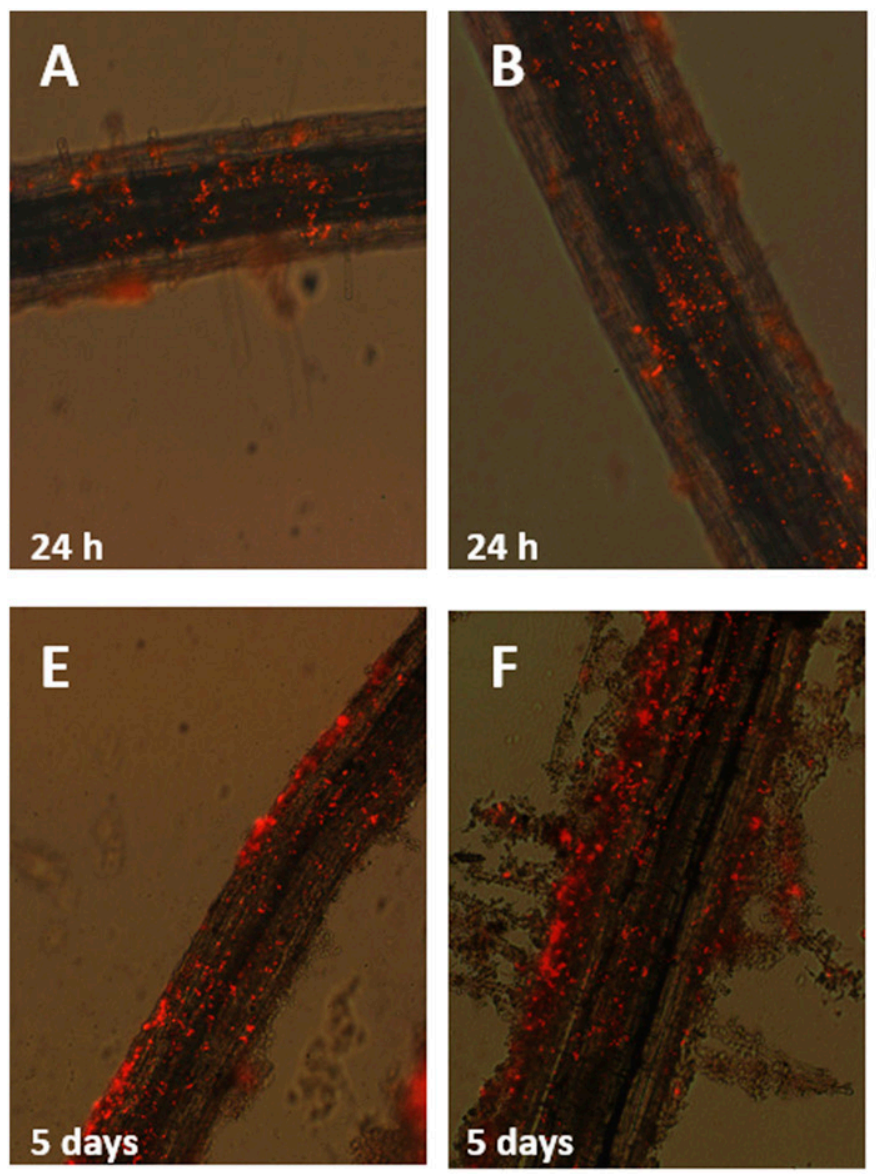

70V-WTR

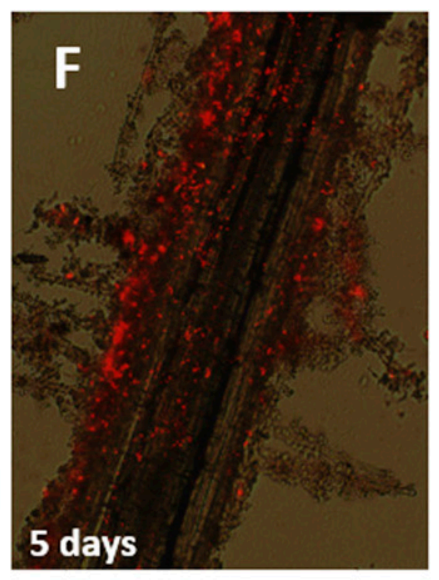

Vd6ADM1R
Minimal medium (Puhalla and Mayfield 1974) was used for measuring colony growth. Conidial production at $25^{\circ} \mathrm{C}$ was assessed under two culture conditions: i) culturing on PDA for 20 days and ii) shaking (140 rpm) in liquid SSN medium (Sinha and Wood 1968). Spores produced in SSN medium were used to observe spore germination and infect plants. Ethylene production was measured after culturing in liquid Czapek-Dox medium (Oxoid) supplemented with $10 \mathrm{mM}$ methionine (Sigma-Aldrich) by shaking $(140 \mathrm{rpm})$ at $25^{\circ} \mathrm{C}$.

\section{Nucleic acid manipulation.}

Fungal genomic DNA was extracted as previously reported (Cary et al. 2009) with a few modifications. After culturing on PDA for 7 days at $25^{\circ} \mathrm{C}$, mycelia were scraped off and were placed in a $1.5-\mathrm{ml}$ tube. The mycelia were macerated, using a mini plastic pestle after adding $700 \mu \mathrm{l}$ of LETS buffer $(0.1 \mathrm{M}$ $\mathrm{LiCl}, 20 \mathrm{mM}$ EDTA, $10 \mathrm{mM}$ Tris-HCl), were mixed by inversion, and were incubated at room temperature for $5 \mathrm{~min}$. After adding $700 \mu \mathrm{l}$ of phenol/chloroform/isoamyl alcohol (25:24:1), they were mixed by inversion and were centrifuged at $16,000 \times g$ at $4^{\circ} \mathrm{C}$ for $15 \mathrm{~min}$. The supernatant was transferred to a new tube, and $1 \mathrm{ml}$ of $95 \%$ ethanol was added. Nucleic acids were precipitated by centrifugation at $16,000 \times g$ for $10 \mathrm{~min}$ at room temperature, were washed with $500 \mu \mathrm{l}$ of $70 \%$ ethanol, were dried at room temperature for $5 \mathrm{~min}$, and were resuspended in $30 \mu \mathrm{l}$ of distilled water. For quantification of fungal biomass in tomato stems, total genomic DNA was isolated as described by Dellaporta et al. (1983).

DNA amplification for gene manipulation was performed using Kapa HiFi DNA polymerase (Kapa Biosystems). PCR
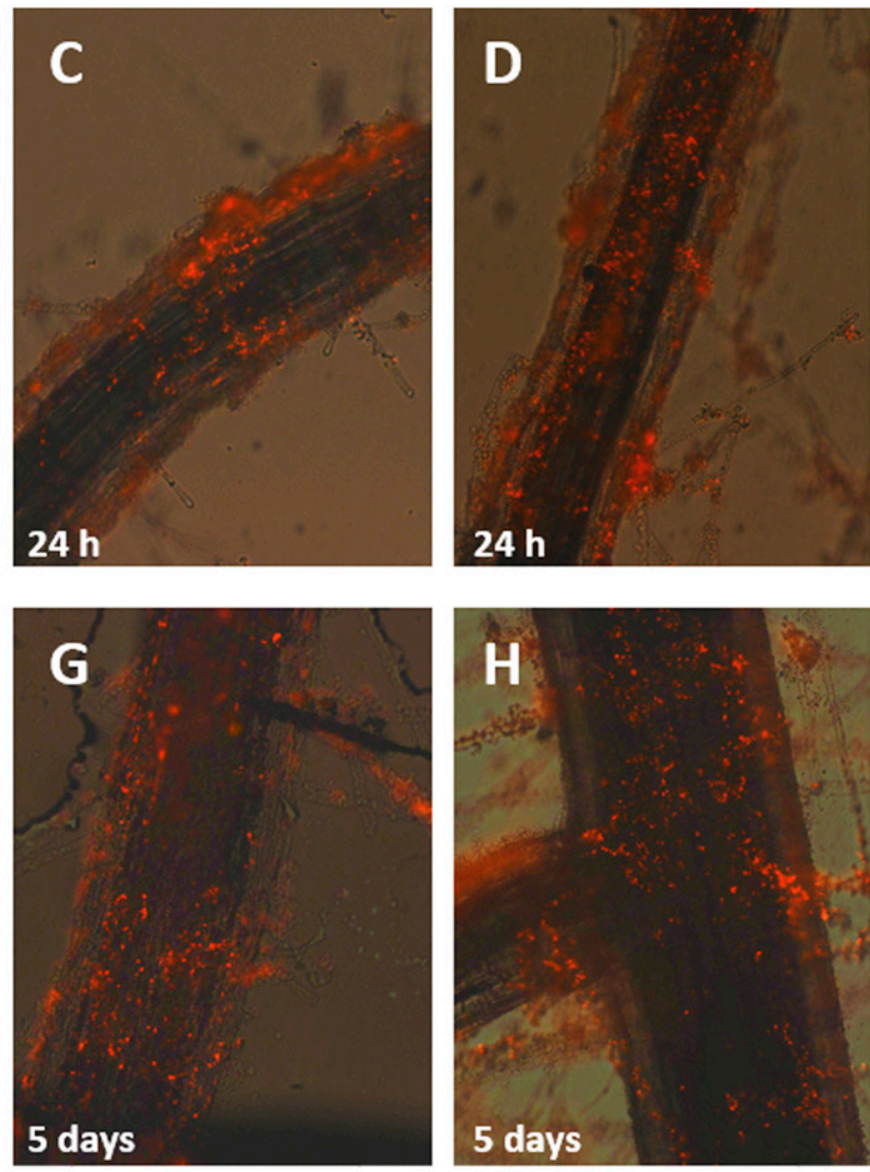

$70 \triangle A D 1.4 R$

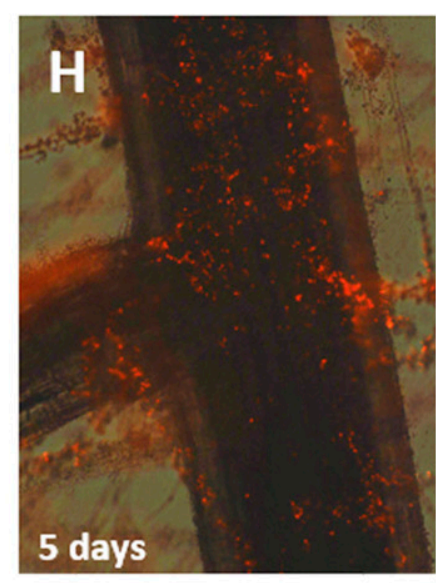

$70 \Delta A D 3.4 R$

Fig. 7. Microscopic observation of tomato root colonization by 70V-WTR, Vd6ADM1R, 70 $\triangle A D 1.4 R$, and 70 $\triangle A D 3.4 R$. A to D, Root surface was imaged at 1 and $\mathbf{E}$ to $\mathbf{H}, 5$ days postinoculation. Magnification used for A to $\mathrm{E}$ was $200 \times$, whereas for F, G, and $\mathrm{H}$, it was $400 \times$. 
conditions included i) one cycle of $95^{\circ} \mathrm{C}$ for $3 \mathrm{~min}$, ii) 35 cycles of $98^{\circ} \mathrm{C}$ for $20 \mathrm{~s}, 72^{\circ} \mathrm{C}$ for $15 \mathrm{~s}$, and $72^{\circ} \mathrm{C}$ for $30 \mathrm{~s}$, and iii) one cycle of $72^{\circ} \mathrm{C}$ for $1 \mathrm{~min}$. Transformants were screened by PCR with Kapa polymerase (Kapa Biosystems), using the following conditions: i) one cycle of $95^{\circ} \mathrm{C}$ for $3 \mathrm{~min}$, ii) 35 cycles of $95^{\circ} \mathrm{C}$ for $30 \mathrm{~s}, 60^{\circ} \mathrm{C}$ for $45 \mathrm{~s}, 72^{\circ} \mathrm{C}$ for $3 \mathrm{~min}$, and iii) one cycle of $72^{\circ} \mathrm{C}$ for $1 \mathrm{~min}$. Escherichia coli DH5a was used for plasmid propagation. Plasmid DNA isolation, digestion with restriction enzymes, ligation, and E. coli transformation were performed as described by Sambrook et al. (1989).

Total RNA was extracted from mycelia ground in the presence of liquid nitrogen, using RNAiso plus reagent (Takara). RNA samples were treated with DNase (HT Biotechnology) to eliminate DNA contamination. First-strand complementary (c)DNAs were synthesized using the PrimeScript RT kit (Takara).

Vector construction and fungal transformation.

A construct for overexpressing $A C C d$ was prepared. Primers ACD_OX_F and ACD_OS_R (Table 1) were used to amplify the ORF of ACCd $(1,038 \mathrm{bp})$. ACD_OX_F and ACD_OS_R contained the $X b a \mathrm{I}$ and $S p h \mathrm{I}$ restriction sites, respectively, at the $5^{\prime}$ end to facilitate cloning of the ORF between the Magnaporthe oryzae ribosomal protein promoter and the Neurospora crassa $\beta$-tubulin terminator in vector $\mathrm{pSK} 1226$. The resulting construct ( $1,835 \mathrm{bp})$ was cloned between the EcoRI and HindIII sites of binary vector pSK879, which carries the geneticin resistance cassette, to produce p1226VdAD. This plasmid was introduced into A. tumefaciens AGL1 for fungal transformation. Transformation of 70V-WT was performed as described by Mullins et al. (2001) with the following modifications. i) Cocultivation of spores and A. tumefaciens cells was performed on a positively charged nylon membrane (Porablot NY Plus, Macherey-Nagel), and ii) PDA amended with $50 \mu \mathrm{g}$ of geneticin or hygromycin $\mathrm{B}$ per milliliter, $100 \mu \mathrm{g}$ of moxalactam per milliliter, and $200 \mu \mathrm{M}$ cefotaxime was used to select transformants. Transformants were purified via single-spore isolation.

Construction of a mutant allele for disrupting $A C C d$ was done. Primer pairs ACD_EX-F1/ACD_K-R1 and ACD_XF2/ACD_H-R2 (Table 1) were used to amplify the promoter (827 bp) and terminator $(864 \mathrm{bp})$ regions of the gene, respectively. The amplified regions were cloned into the $5^{\prime}$ and $3{ }^{\prime}$ ends of the geneticin resistance gene in vector pSK666 (Tzima et al. 2010). The resulting mutant allele $(3,171 \mathrm{bp})$ was amplified with primers ACD-P_F1 and ACD_H-R2 and was cloned between the PstI and HindIII sites of binary vector pGKO2 (Khang et al. 2005), which carries the herpes simplex virus thymidine kinase gene as a negative selection marker

A
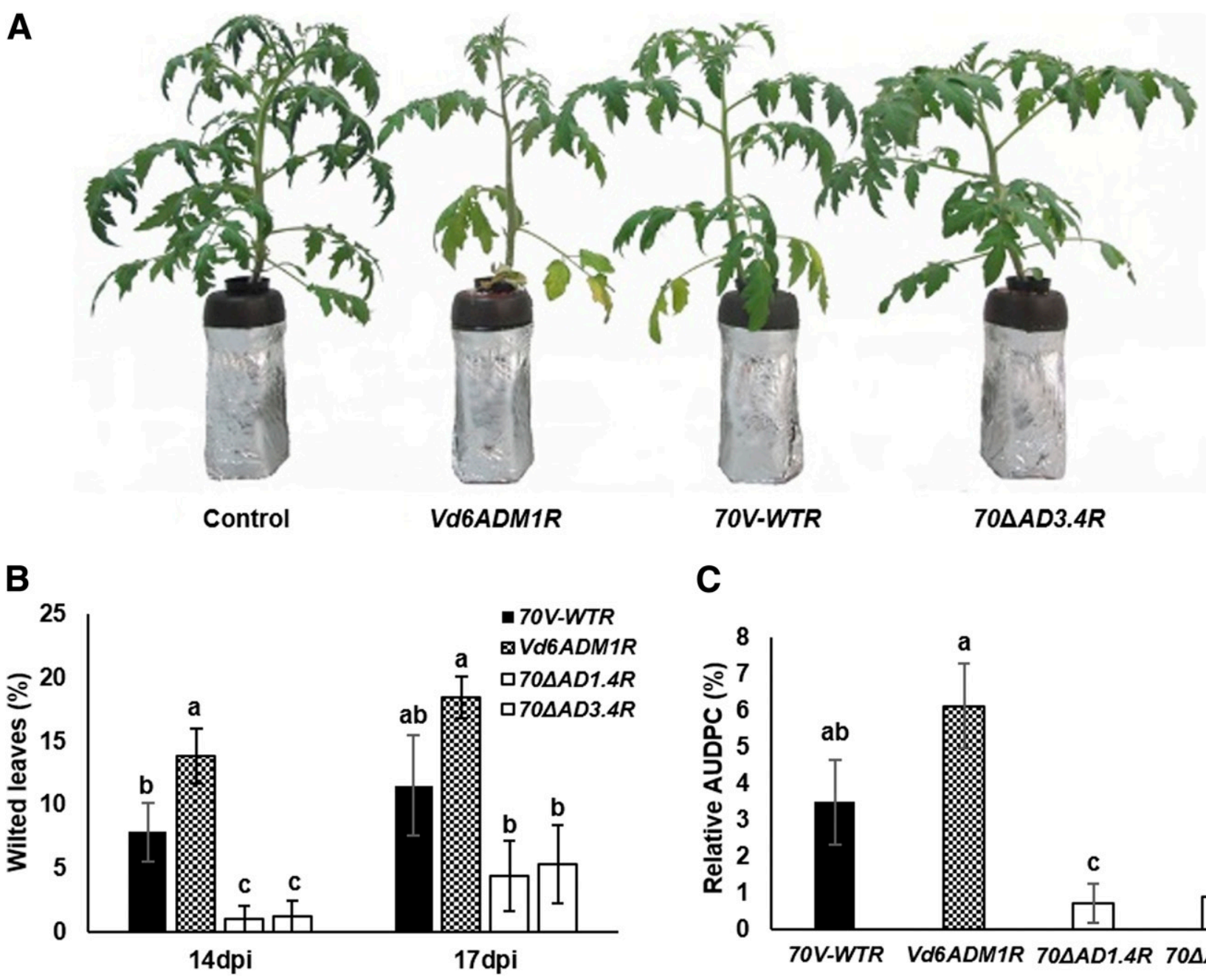

C

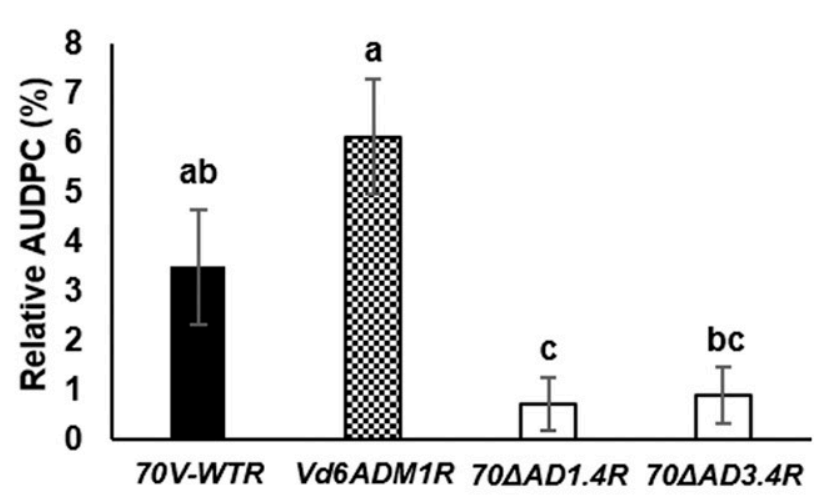

Fig. 8. Disease severity of tomato plants infected with 70V-WT and 1-aminocyclopropane-1-carboxylic acid deaminase $(A C C d)$ mutants in a hydroponic system. A, Tomato plants at 17 days after inoculation with 70V-WTR, Vd6ADM1R, and 70 $A D D 3.4 R$. B, Disease progression at 14 and 17 days postinoculation and $\mathbf{C}$, the amount of disease expressed as relative area under the disease progress curve. Vertical bars indicate the calculated standard errors based on six replicates. All values were subjected to analysis of variance. Different letters in B and C indicate statistically significant differences according to Tukey's multiple range test at $P \leq 0.05$. 
against ectopic transformants. The resulting plasmid pGVdAD in A. tumefaciens AGL1 was used for disrupting ACCd. Transformants were selected as described above except that $50 \mu \mathrm{M}$ 5-fluoro-2-deoxyuridine (Sigma-Aldrich) was used to select against ectopic transformants (Khang et al. 2005).

For complementation, a 2,728-bp fragment that covers the $A C C d$ gene, including the $5^{\prime}$ (1,000 bp) and 3' (600 bp) regions flanking the ORF, was amplified from 70V-WT, using primers ACD_X-C-F1 and ACD_H-R2 (Table 1). The resulting PCR product was cloned between the $\mathrm{XbaI}$ and HindIII sites of pSK561 (Tzima et al. 2010), a binary vector that carries a hygromycin resistance gene cassette.

\section{Molecular characterization of resulting mutants.}

Deletion and complemented mutants were identified by PCR, using primers ACD_EX-F1 and ACD_H-R2 (Table 1). Transcripts from $A C C d$ in deletion mutants were determined via reverse transcription (RT)-PCR, using ACD_OX_F and ACD_OS_R primers on cDNAs. ACCd transcripts in overexpression strains and transcripts from other genes involved in ethylene biosynthesis were measured by real-time qRT-PCR analysis. The $V$. dahliae $\beta$-tubulin gene was used as an internal standard. Primers used are listed in Table 1. Averaged threshold cycle values derived from three independent biological samples were calculated for each gene (Pfaffl 2001).

Analysis of growth and developmental characteristics.

For each strain, a $20-\mu$ l conidial suspension $\left(1 \times 10^{6}\right.$ conidia per milliliter) was spot-inoculated on minimal medium (five plates per strain) and was incubated at $25^{\circ} \mathrm{C}$. Colony diameter and morphology were examined at $8,10,12,14,16$, and $21 \mathrm{dpi}$. For conidial production, individual strains were cultured on PDA at $25^{\circ} \mathrm{C}$ for 20 days (three plates per strain). After adding $4 \mathrm{ml}$ of sterilized water to each plate, the surface was rubbed using a sterile swab and plates were shaken gently to release conidia. A hemocytometer was used to count the number of conidia in the $20-\mu$ conidial suspension, using a light microscope (Axiostar plus; Carl Zeiss International). Results were presented as the
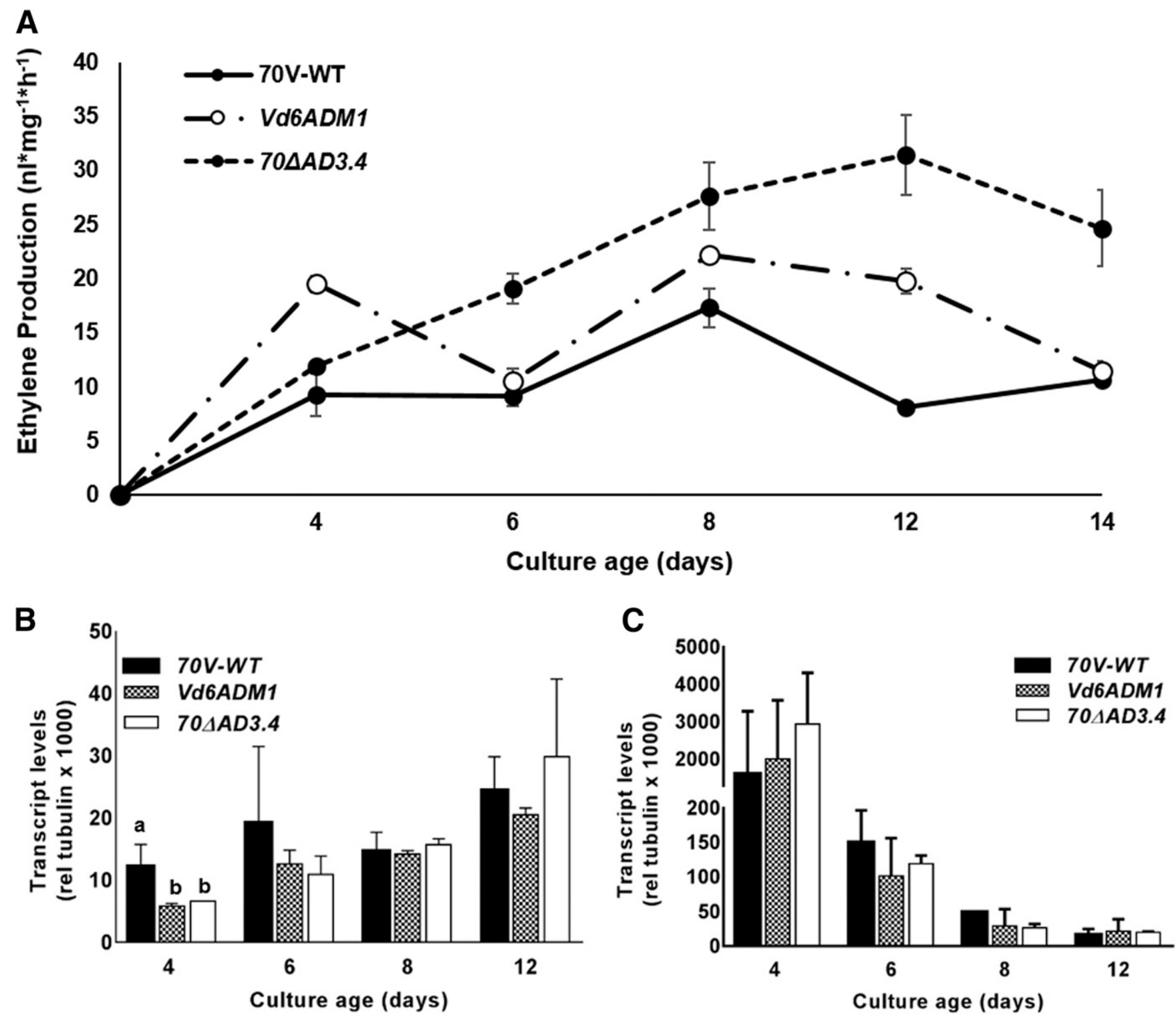

Fig. 9. Ethylene production and expression of two genes involved in ethylene biosynthesis. A, Ethylene production over time by 70V-WT, overexpression strain $V d 6 A D M 1$, and deletion mutant 70 $A A D 3.4$. B, Transcript levels of the ACC synthase and $\mathbf{C}$, ethylene-forming enzyme genes over time. Vertical bars indicate the calculated standard errors of three replicates. All values were subjected to analysis of variance. For data that showed a significance level of $P \leq 0.05$, Tukey's post hoc analysis was also performed. 
number of conidia produced per square centimeter of individual colonies.

Conidial production in liquid SSN medium was quantified by inoculating a $300-\mu l$ spore suspension $\left(1 \times 10^{6}\right.$ conidia per milliliter) into $100 \mathrm{ml}$ of medium in a 250-ml Erlenmeyer flask (three flasks per strain) and shaking $(150 \mathrm{rpm})$ at $25^{\circ} \mathrm{C}$. After 7 days, the number of spores produced was counted as described above. The spore germination rate was determined by placing a $10-\mu l$ spore suspension $\left(1 \times 10^{6}\right.$ conidia per milliliter $)$ on sterile glass slides (three slides per strain) and, subsequently, observing approximately 100 conidia per slide after 12,16 , and $20 \mathrm{~h}$ of incubation at $25^{\circ} \mathrm{C}$ under $100 \%$ humidity. Individual strains were cultured on PDA supplemented with $0,10,100$, and $500 \mu \mathrm{M}$ ACC to evaluate the effect of ACC on colony growth and spore production.

\section{Conditions for plant growth and infection.}

Seeds of two tomato (Solanum lycopersicum) lines, including $\mathrm{Nr}$ (obtained from the Tomato Genetics Resource Center at the University of California, Davis) and cultivar Ailsa Craig, and eggplant (Solanum melongena cv. Black Beauty) were stored at $4^{\circ} \mathrm{C}$. For infection assays in a growth room, seedlings grown in plastic trays were transplanted to $10.5 \mathrm{~cm}$-diameter pots (Teku VCG), with each pot containing approximately $450 \mathrm{ml}$ of soil (Plantaflor Potting Soil). These pots were placed in a growth room set at 65 to $70 \%$ relative humidity, $25^{\circ} \mathrm{C}$, and a $16-\mathrm{h}$ photoperiod, with a photon flux density of $200 \pm 20 \mu \mathrm{mol} \mathrm{m}{ }^{-2}$ $\mathrm{s}^{-1}$. Plants were watered every 2 days to maintain approximately $70 \%$ soil humidity. For infection assays in a greenhouse, seeds were sown directly in the same pots and plants were watered as needed.

Five-day-old fungal culture in SSN medium was passed through cheesecloth to remove mycelia, and the conidial concentration was adjusted to $1 \times 10^{7}$ conidia per milliliter. Each seedling was inoculated with a $10-\mathrm{ml}$ conidial suspension via root drenching when they reached the four-leaf (tomato) or two-leaf stage (eggplant) stage.

Disease severity was measured, based on the number of wilted leaves, as a percentage of the total number of leaves for each plant. Symptoms were recorded for up to 19 days and were plotted over time to generate the AUDPC, using the trapezoidal integration method (Campbell and Madden 1990). Disease was expressed as a percentage of the maximum possible area for the whole period of each experiment, referred to as relative AUDPC. Plant height and fresh weight were also measured. The experiments were repeated two times with 12 (growth room) and five (greenhouse) plants per experiment for tomato and 10 seedlings per experiment for eggplant.

The effect of ACC on disease development was evaluated by applying a solution of $100 \mu \mathrm{M}$ ACC by root drenching $(10 \mathrm{ml}$ per plant) two-week-old plants $12 \mathrm{~h}$ prior to fungal inoculation. Pathogen inoculation was performed as described above. Six plants per treatment were used, and the experiment was repeated twice. Symptoms were recorded for up to 20 days.

Hydroponically grown plants were also infected to observe root attachment and colonization by individual $V$. dahliae strains. Tomato seedlings grown in plastic trays were transplanted to 1-liter containers (one plant per container), containing complete nutrient solution, at the first-leaf stage. Containers were covered with aluminum foil (Fig. 8) to prevent algae growth and temperature fluctuation. Plants were grown for 2 weeks to allow recovery from transplanting stress. Complete nutrient solution consisted of the following minerals: $\mathrm{NO}_{3}^{-}=14.29, \mathrm{~K}=8.43, \mathrm{PO}_{4}^{-3}=1.07, \mathrm{Ca}=6.96, \mathrm{Mg}=2.93$, $\mathrm{SO}_{4}^{-2}=1.56, \mathrm{Na}=1.91 \mathrm{mmol}$ per liter, respectively, and $\mathrm{B}=$ $25.00, \mathrm{Fe}=20.85, \mathrm{Mn}=10.00, \mathrm{Cu}=0.77, \mathrm{Zn}=3.85$, and $\mathrm{Mo}=$
$0.52 \mu$ mol per liter, respectively (Marinou et al. 2013). At the end of the second week, six plants were inoculated with conidia at the final concentration of $1 \times 10^{6}$ conidia per milliliter. Additional nutrient solution was added weekly. The $\mathrm{pH}$ and
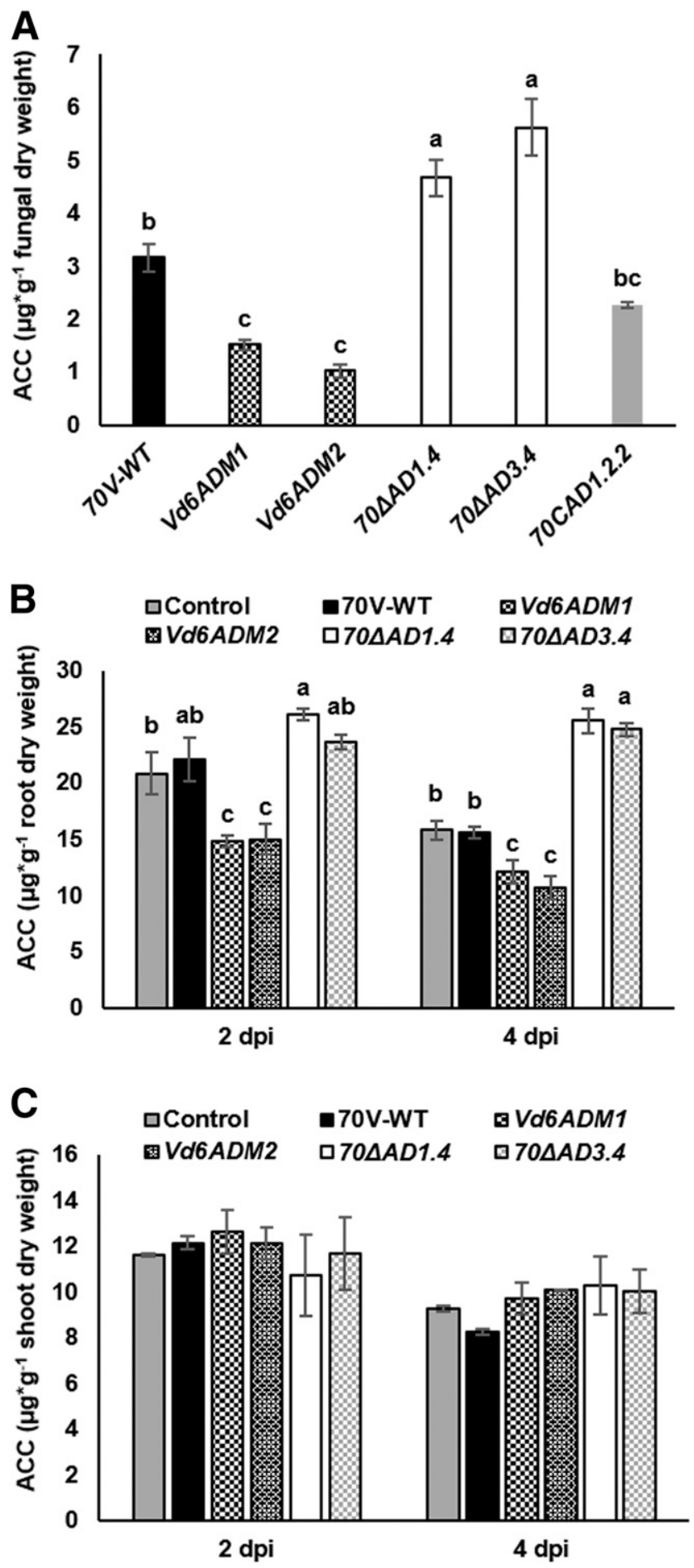

Fig. 10. Effect of 1-aminocyclopropane-1-carboxylic acid deaminase $(A C C d)$ mutations on the amount of ACC in $V$. dahliae and infected tomato. A, The amounts of ACC in 70V-WT, ACCd deletion mutants (70 $\triangle A D 1.4$ and 70 $\triangle A D 3.4$ ), overexpression strains (Vd6ADM1 and Vd6ADM2), and complemented deletion mutant 70CAD1.2.2, after 7 days of culture. B, The amount of ACC in roots and $\mathbf{C}$, shoots of mock-inoculated tomato plants and plants infected with 70V-WT, Vd6ADM1, Vd6ADM2, 70 $\triangle A D 1.4$, and $70 \triangle A D 3.4$ mutants. Vertical bars indicate the calculated standard errors of three replicates. All values were subjected to analysis of variance. For data that showed a significance level of $P \leq 0.05$, Tukey's post hoc analysis was also performed. 
electric conductivity of the solution were maintained at 5.8 and $2.1 \mathrm{mS} \mathrm{cm}^{-1}$, respectively. Due to the alkalinity of water used, the $\mathrm{pH}$ was measured every third day and was adjusted if needed, using $\mathrm{H}_{2} \mathrm{SO}_{4}$ (5\% vol/vol). Symptoms were recorded at 14 and $17 \mathrm{dpi}$.
Quantification of fungal biomass in planta.

Fungal biomass in infected plants was quantified by qPCR. For each biological sample (pool of three plants per treatment), the above-ground parts of inoculated plants were collected and were ground to a fine powder, using an autoclaved mortar and

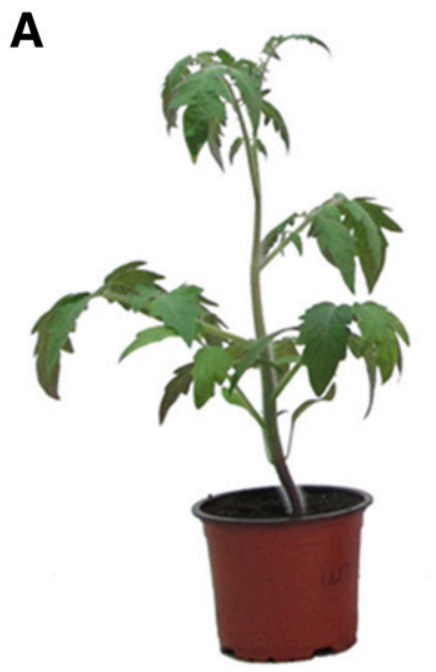

WT

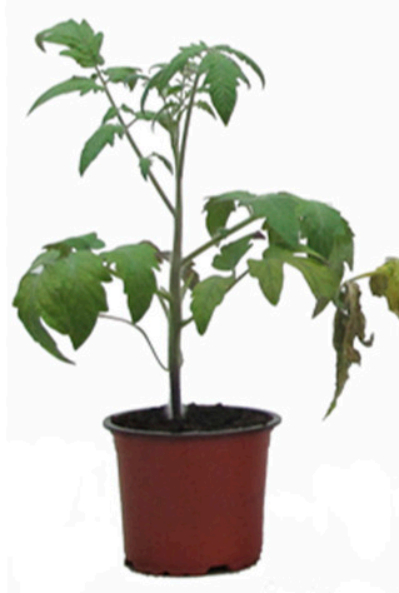

$\mathbf{N r}$

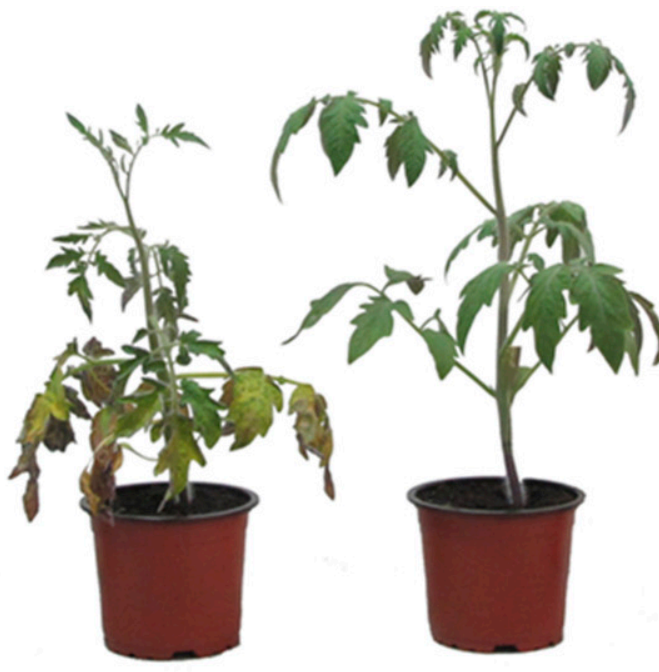

WT+Vd

WT+ACC

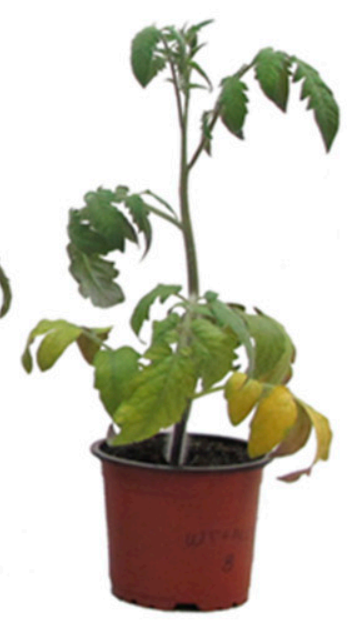

WT+ACC+Vd

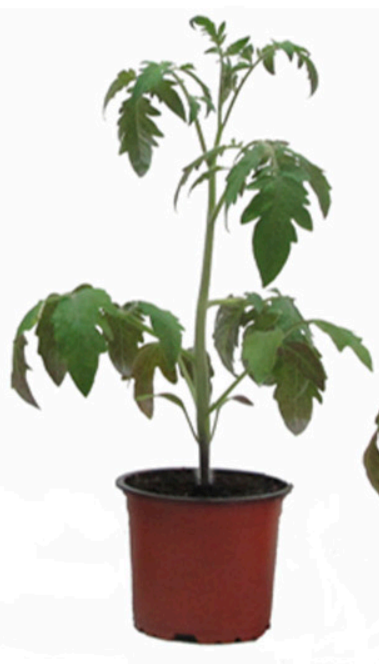

$\mathrm{N} r+\mathrm{ACC}$

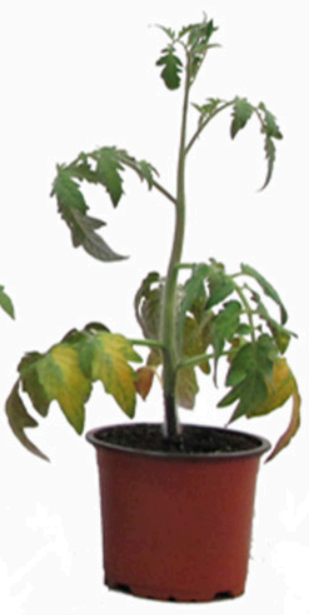

$\mathrm{Nr}+\mathrm{Vd}$

C
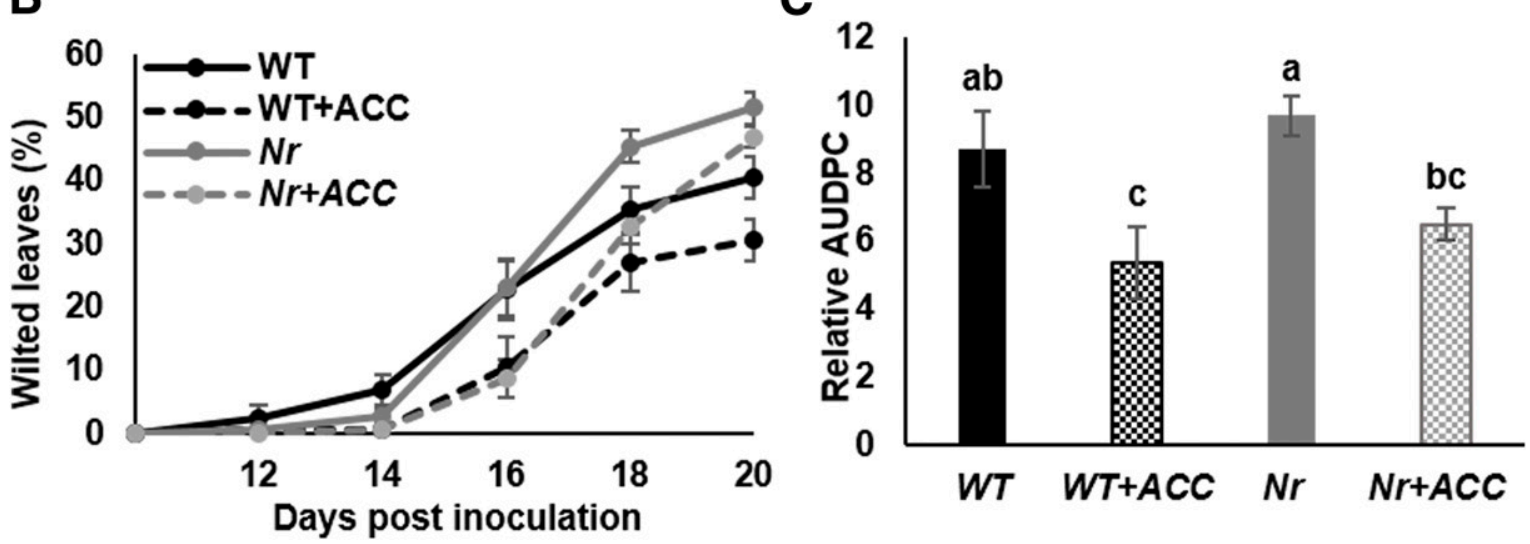

Fig. 11. Effect of 1-aminocyclopropane-1-carboxylic acid deaminase (ACC) treatment on disease development in tomato plants infected with 70V-WT. Plants were treated with $100 \mu \mathrm{M}$ ACC or water by root drenching (10 ml per plant) $12 \mathrm{~h}$ before fungal inoculation. A, Symptoms at 18 days after inoculation, B, disease progress curves, and $\mathbf{C}$, the amount of disease expressed as relative area under the disease progress curve. Vertical bars indicate the calculated standard errors of 12 replicates. All values were subjected to analysis of variance. Different letters in C note statistically significant differences according to Tukey's multiple range test at $P \leq 0.05$. 
pestle, in the presence of liquid nitrogen. DNA was extracted as described above, was quantified using a NanoDrop 2000 spectrophotometer (Thermo Scientific), and was adjusted to $100 \mathrm{ng} \mu \mathrm{l}^{-1}$. qPCR reactions were performed using the IQ5 thermocycler (Bio-Rad) and the Kapa SYBR FAST qPCR kit (Kapa Biosystems). Primers ITS1-F and ST-VE1-R were used for quantifying $V$. dahliae, and the Solanum lycopersicum $\beta$-tubulin gene was used to normalize the amount of fungal DNA in different samples (Table 1).

\section{Microscopic observation of root infection.}

To compare root attachment by conidia and colonization during early stages of infection between 70V-WT and its mutants, hydroponically grown tomato plants were infected with spores of $70 \mathrm{~V}-\mathrm{WTR}, V d 6 A D M 1 R, 70 \triangle A D 1.4 R$, and $70 \Delta A D 3.4 R$, transformants of 70V-WT, Vd6ADM1, 70 $\triangle A D 1.4$, and $70 \Delta A D 3.4$ with the AsRed gene under the control of the Fusarium verticillioides elongation factor $1 \alpha$ promoter (Kim et al. 2011). At 1 and 5 dpi, plants were removed, were washed with distilled water, and the root surface was imaged using a Zeiss Axio Imager D1 epifluorescence microscope equipped with a Zeiss AXIO Cam MRc5 camera (Carl Zeiss International). Filter sets used for observing AsRed were $576 \mathrm{~nm}$ (excitation) and $592 \mathrm{~nm}$ (emission). Collected images were stored as jpeg files and were processed using Adobe Photoshop CS software (Adobe Systems Inc.).

\section{Ethylene production.}

Individual strains were cultured in a 50-ml Erlenmeyer flask containing $20 \mathrm{ml}$ of Czapek Dox broth supplemented with $10 \mathrm{mM}$ methionine (all strains) and $50 \mu \mathrm{g}$ of geneticin or hygromycin (only for transformants) per milliliter. Flasks inoculated with $10^{6}$ conidia were placed in an orbital shaker $(150 \mathrm{rpm})$ at $25^{\circ} \mathrm{C}$. Before ethylene measurement, each culture flask was flushed with air to eliminate any accumulated ethylene. After sealing the flask with a rubber stopper for $1 \mathrm{~h}$, a syringe was used to collect headspace air. The amount of ethylene in a 1-ml air sample was measured using a 7890A Agilent gas chromatographer (Agilent Technologies) equipped with a fl ame ionization detector and an Agilent stainless steel column $(2 \mathrm{~mm}$ id $\times 2 \mathrm{~m}$ ) packed with Porapak Q 80/100 mesh, as described by Petrou et al. (2013), with minor modifications.
Helium was used as a carrier gas under a constant inlet pressure of $20 \mathrm{psi}$. Inlet and oven temperatures were maintained at $80^{\circ} \mathrm{C}$, and the detector temperature was set at $200^{\circ} \mathrm{C}$. The total run time was $3 \mathrm{~min}$, with ethylene being detected at $1.8 \mathrm{~min}$. Calibration was performed using ethylene at $1 \mathrm{ppm}$. After collecting headspace air, mycelia and conidia in each flask were harvested by centrifugation and were lyophilized to determine dry weight. Ethylene production rate was calculated as nanoliters of ethylene produced per hour per gram. The experiment was repeated twice, and the data shown correspond to the averages of three independent biological samples.

\section{ACC measurement in fungal and plant tissues.}

For quantifying the amount of ACC in $V$. dahliae 70V-WT and its $A C C d$ transformants, they were cultured in liquid SSN medium at $25^{\circ} \mathrm{C}$ by shaking ( $140 \mathrm{rpm}$ ) for 7 days, and harvested spores and mycelia were freeze-dried for $48 \mathrm{~h}$. The amount of ACC was also determined in roots and shoots of tomato plants i) inoculated with $70 \mathrm{~V}-\mathrm{WT}$ and $A C C d$ transformants as described above and ii) root-drenched with $10 \mathrm{ml}$ of $100 \mu \mathrm{M} \mathrm{ACC}$. Plants were uprooted 2 and 4 days after infection and $12 \mathrm{~h}$ after ACC treatment, respectively, were rinsed thoroughly with sterile, deionized water, and were lyophilized for 5 days. All samples were immediately frozen by immersing them in liquid nitrogen before freeze-drying. The amount of ACC was measured using the method described by Lizada and Yang (1979), in which the amount of ACC formed was measured via its conversion to ethylene. Ethylene was determined by gas chromatography as described above. Fungal ACC contents shown correspond to the averages of three independent biological samples. For plant ACC determination, three biological samples (pool of two plants per treatment) were used.

\section{Statistical analysis.}

Statistical analyses were performed using $R$ package ( $R$ 2016, version 3.3.1). Data obtained in all experiments were subjected to analysis of variance, and significant differences between individual means were then determined using Tukey's post hoc pairwise comparison test at the $5 \%$ confidence level. Dunnett's multiple comparisons test was used for analyzing gene expression data.

Table 1. Primers used in this study

\begin{tabular}{|c|c|c|c|}
\hline Name & Sequence $^{\mathrm{a}}$ & Target $^{\mathbf{b}}$ & Reference \\
\hline ACD_EX-F1 & 5'-ATGAATTCATTCAGGCGGTATCCAGGTCAACAACA-3' & ACCd (VDAG_10392) & This study \\
\hline ACD_P-F1 & 5'- ATCTGCAGAGGCGGTATCCAGGTCAACAACA-3' & & This study \\
\hline ACD_K-R1 & 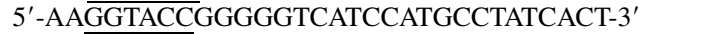 & & This study \\
\hline $\mathrm{ACD} \mathrm{X}_{-}-\mathrm{F} 2$ & 5'-AATCTAGCGGAGGGCGACATCACA-3' & & This study \\
\hline ACD_H-R2 & 5'-TTTAAGCTTCATCCTCCACCTGGGCTCTTTC-3' & & This study \\
\hline ACD_X-C-F1 & 5'-ATTCTAGAAGGCGGTATCCAGGTCAACAACA-3' & & This study \\
\hline ACD_OX_F & 5'-CCACGATCTAGACCACACCACCACCACATC-3' & & This study \\
\hline ACD_OS_R & 5'-CCATTTGCATGCATTGACCCTCGCCCTCTC-3' & & This study \\
\hline ACD_Rt1_F & 5'-GCCAA $\overline{A C G C G A G G A C T G C-3 ' ~}$ & & This study \\
\hline ACD_Rt1_R & 5'-CACGCCGCCAATGCTGAC-3' & & This study \\
\hline ACS_Rt1_F & 5'-AACTCGGGCCGCCACAACATT-3' & ACS (VDAG_05021.1) & This study \\
\hline ACS_Rt1_R & 5'-ACAGGGCGCGGAGCAAGGAT-3' & & This study \\
\hline EFE_RT1_F & 5'-ACGACGTCGGTGCCCTGTTTGTTC-3' & Ethylene/succinate forming enzyme & This study \\
\hline EFE_RT1_R & 5'-TGCGCTGGGGGTAGTTCCTGATGA-3' & (VDAG_09492.1) & This study \\
\hline ITS1-F & 5'-AAAGTTTTAATGGTTCGCTAAGA-3' & ITS1 & Gardes and Bruns 1993 \\
\hline ST-VE1-R & 5'-CTTGGTCATTTAGAGGAAGTAA-3' & 18S rDNA & Lievens et al. 2006 \\
\hline VdBt-F & 5'-TTCCCCCGTCTCCACTTCTTCATG-3' & $\beta$-tubulin (VDAG_10074.1) & Tzima et al. 2012 \\
\hline VdBt-R & 5'-GACAAGATCGTTCATGTTGGACTC-3' & & \\
\hline LeTUB-F & 5'-GATTTGCCCACTAACCTCTCGT-3' & $\beta$-tubulin gene (DQ205342) & Pantelides et al. 2010 \\
\hline LeTUB-R & 5'-ACCTCCTTTGTGCTCATCTTACCC-3' & & \\
\hline
\end{tabular}

\footnotetext{
${ }^{\mathrm{a}}$ Underlined sequences correspond to restriction enzyme sites introduced to facilitate subsequent cloning.

${ }^{\mathrm{b}}$ With the exception of LeTUB-F and LeTUB-R, all primers correspond to Verticillium dahliae genes.
} 


\section{ACKNOWLEDGMENTS}

We acknowledge N. Tzortzakis and A. Chrysargyris for helping with the hydroponic infection assays and A. Triantafyllopoulou for supporting the greenhouse work.

\section{LITERATURE CITED}

Abeles, F. B., Morgan, P. W., and Saltveit, M. E. 1992. Ethylene in Plant Biology, 2nd Ed. Academic Press, San Diego, CA, U.S.A.

Adams, D. O., and Yang, S. F. 1979. Ethylene biosynthesis: Identification of 1-aminocyclopropane-1-carboxylic acid as an intermediate in the conversion of methionine to ethylene. Proc. Natl. Acad. Sci. U.S.A. 76:170-174.

Al-Masri, M. I., Elad, Y., Sharon, A., and Barakat, R. 2006. Ethylene production by Sclerotinia sclerotiorum and influence of exogenously applied hormone and its inhibitor aminoethoxyvinylglycine on white mold. Crop Prot. 25:356-361.

Belimov, A. A., Dodd, I. C., Safronova, V. I., Hontzeas, N., and Davies, W. J. 2007. Pseudomonas brassicacearum strain Am3 containing 1aminocyclopropane-1-carboxylate deaminase can show both pathogenic and growth-promoting properties in its interaction with tomato. J. Exp. Bot. 58:1485-1495.

Bhat, R. G., and Subbarao, K. V. 1999. Host range specificity in Verticillium dahliae. Phytopathology 89:1218-1225.

Billington, D. C., Golding, B. T., and Primrose, S. B. 1979. Biosynthesis of ethylene from methionine. Isolation of the putative intermediate 4 methylthio-2-oxobutanoate from culture fluids of bacteria and fungi. Biochem. J. 182:827-836.

Campbell, C. L., and Madden, L. V. 1990. Introduction to Plant Disease Epidemiology. John Wiley and Sons Inc., New York.

Cary, J. W., Ehrlich, K. C., Beltz, S. B., Harris-Coward, P., and Klich, M. A. 2009. Characterization of the Aspergillus ochraceoroseus aflatoxin/sterigmatocystin biosynthetic gene cluster. Mycologia 101:352-362.

Chagué, V. 2010. Ethylene Production by Fungi: Biological Questions and Future Developments Towards a Sustainable Polymers Industry. Pages 3011-3020 in: Handbook of Hydrocarbon and Lipid Microbiology. K. N. Timmis, T. J. McGenity, J. R. van der Meer, and V. de Lorenzo, eds. Springer-Verlag, Berlin.

Chagué, V., Danit, L.-V., Siewers, V., Schulze-Gronover, C., Tudzynski, P., Tudzynski, B., and Sharon, A. 2006. Ethylene sensing and gene activation in Botrytis cinerea: A missing link in ethylene regulation of fungus-plant interactions? Mol. Plant-Microbe Interact 19:33-42.

Chagué, V., Elad, Y., Barakat, R., Tudzynski, P., and Sharon, A. 2002. Ethylene biosynthesis in Botrytis cinerea. FEMS Microbiol. Ecol. 40:143-149.

Cheng, Z., Park, E., and Glick, B. R. 2007. 1-Aminocyclopropane-1carboxylate deaminase from Pseudomonas putida UW4 facilitates the growth of canola in the presence of salt. Can. J. Microbiol. 53:912-918.

Cristescu, S. M., De Martinis, D., Te Lintel Hekkert, S., Parker, D. H., and Harren, F. J. M. 2002. Ethylene production by Botrytis cinerea in vitro and in tomatoes. Appl. Environ. Microbiol. 68:5342-5350.

Cronshaw, D. K., and Pegg, G. F. 1976. Ethylene as a toxin synergist in Verticillium wilt of tomato. Physiol. Plant Pathol. 9:33-44.

Davis, M. E., Miller, A. R., and Lineberger, R. D. 1992. Studies on the effects of ethylene on transformation of tomato cotyledons (Lycopersicon esculentum Mill.) by Agrobacterium tumefaciens. J. Plant Physiol. 139:309-312.

Dellaporta, S. L., Wood, J., and Hicks, J. B. 1983. A plant DNA minipreparation: Version II. Plant Mol. Biol. Report. 1:19-21.

Ezura, H., Yuhashi, K. I., Yasuta, T., and Minamisawa, K. 1999. Effect of ethylene on Agrobacterium tumefaciens mediated gene transfer to melon. Plant Breed. 119:75-79.

Fradin, E. F., and Thomma, B. P. H. J. 2006. Physiology and molecular aspects of Verticillium wilt diseases caused by $\mathrm{V}$. dahliae and V. alboatrum. Mol. Plant Pathol. 7:71-86.

Fukuda, H., Fujii, T., and Ogawa, T. 1986. Preparation of a cell-free ethyleneforming system from Penicillium digitatum. Agric. Biol. Chem. 50:977-981.

Gardes, M., and Bruns, T. D. 1993. ITS primers with enhanced specificity for basidiomycetes-Application to the identification of mycorrhizae and rusts. Mol. Ecol. 2:113-118.

Glick, B. R. 2014. Bacteria with ACC deaminase can promote plant growth and help to feed the world. Microbiol. Res. 169:30-39.

Glick, B. R., Penrose, D. M., and Li, J. 1998. A model for the lowering of plant ethylene concentrations by plant growth-promoting bacteria. J. Theor. Biol. 190:63-68.

Grichko, V. P., Filby, B., and Glick, B. R. 2000. Increased ability of transgenic plants expressing the bacterial enzyme ACC deaminase to accumulate $\mathrm{Cd}, \mathrm{Co}, \mathrm{Cu}, \mathrm{Ni}, \mathrm{Pb}$, and $\mathrm{Zn}$. J. Biotechnol. 81:45-53.
Honma, M., and Shimomura, T. 1978. Metabolism of 1-aminocyclopropane1-carboxylic acid. Agric. Biol. Chem. 42:1825-1831.

Hottiger, T., and Boller, T. 1991. Ethylene biosynthesis in Fusarium oxysporum f. sp. tulipae proceeds from glutamate/2-oxoglutarate and requires oxygen and ferrous ions in vivo. Arch. Microbiol. 157:18-22.

Husen, E., Wahyudi, A. T., Suwanto, A., and Giyando. 2011. Growth enhancement and disease reduction of soybean by 1-aminocyclopropane-1-carboxylate deaminase-producing Pseudomonas. Am. J. Appl. Sci. 8:1073-1080.

Jia, Y. J., Kakuta, Y., Sugawara, M., Igarashi, T., Oki, N., Kisaki, M., Shoji, T., Kanetuna, Y., Horita, T., Matsui, H., and Honma, M. 1999. Synthesis and degradation of 1-aminocyclopropane-1-carboxylic acid by Penicillium citrinum. Biosci. Biotechnol. Biochem. 63:542-549.

Johnson, P. R., and Ecker, J. R. 1998. The ethylene gas signal transduction pathway: A molecular perspective. Annu. Rev. Genet. 32:227-254.

Keykhasaber, M., Thomma, B. P. H. J., and Hiemstra, J. A. 2017. Verticillium wilt caused by Verticillium dahliae in woody plants with emphasis on olive and shade trees. Eur. J. Plant Pathol. 150:21-37.

Khang, C. H., Park, S. Y., Lee, Y. H., and Kang, S. 2005. A dual selection based, targeted gene replacement tool for Magnaporthe grisea and Fusarium oxysporum. Fungal Genet. Biol. 42:483-492.

Kim, H.-S., Park, S.-Y., Lee, S., Adams, E. L., Czymmek, K., and Kang, S. 2011. Loss of $c A M P$-dependent protein kinase A affects multiple traits important for root pathogenesis by Fusarium oxysporum. Mol. PlantMicrobe Interact 24:719-732.

Kim, Y. K., Kawano, T., Li, D., and Kolattukudy, P. E. 2000. A mitogenactivated protein kinase kinase required for induction of cytokinesis and appressorium formation by host signals in the conidia of Colletotrichum gloeosporioides. Plant Cell 12:1331-1343.

Klosterman, S. J., Atallah, Z. K., Vallad, G. E., and Subbarao, K. V. 2009. Diversity, pathogenicity, and management of verticillium species. Annu. Rev. Phytopathol. 47:39-62.

Lievens, B., Brouwer, M., Vanachter, A. C. R. C., Cammue, B. P. A., and Thomma, B. P. H. J. 2006. Real-time PCR for detection and quantification of fungal and oomycete tomato pathogens in plant and soil samples. Plant Sci. 171:155-165.

Lizada, M. C., and Yang, S. F. 1979. A simple and sensitive assay for 1aminocyclopropane-1-carboxylic acid. Anal. Biochem. 100:140-145.

Luo, X., Xie, C., Dong, J., Yang, X., and Sui, A. 2014. Interactions between Verticillium dahliae and its host: Vegetative growth, pathogenicity, plant immunity. Appl. Microbiol. Biotechnol. 98:6921-6932.

Marco, S., and Levy, D. 1979. Involvement of ethylene in the development of cucumber mosaic virus-induced chlorotic lesions in cucumber cotyledons. Physiol. Plant Pathol. 14:235-244.

Marinou, E., Chrysargyris, A., and Tzortzakis, N. 2013. Use of sawdust, coco soil and pumice in hydroponically grown strawberry. Plant Soil Environ. 59:452-459.

Maruthachalam, K., Klosterman, S. J., Kang, S., Hayes, R. J., and Subbarao, K. V. 2011. Identification of pathogenicity-related genes in the vascular wilt fungus Verticillium dahliae by Agrobacterium tumefaciens-mediated T-DNA insertional mutagenesis. Mol. Biotechnol. 49:209-221.

Mayak, S., Tirosh, T., and Glick, B. R. 2004. Plant growth-promoting bacteria that confer resistance to water stress in tomatoes and peppers. Plant Sci. 166:525-530.

Mullins, E. D., and Kang, S. 2001. Transformation: A tool for studying fungal pathogens of plants. Cell. Mol. Life Sci. 58:2043-2052.

Nascimento, F. X., Rossi, M. J., and Glick, B. R. 2018. Ethylene and 1aminocyclopropane-1-carboxylate (ACC) in plant-bacterial interactions. Front. Plant Sci. 9:114

Nascimento, F. X., Vicente, C. S. L., Barbosa, P., Espada, M., Glick, B. R. Mota, M., and Oliveira, S. 2013. Evidence for the involvement of ACC deaminase from Pseudomonas putida UW4 in the biocontrol of pine wilt disease caused by Bursaphelenchus xylophilus. BioControl 58: 427-433.

Nonaka, S., and Ezura, H. 2014. Plant-Agrobacterium interaction mediated by ethylene and super-Agrobacterium conferring efficient gene transfer. Front. Plant Sci. 5:681.

Pantelides, I. S., Tjamos, S. E., and Paplomatas, E. J. 2010. Insights into the role of ethylene perception in tomato resistance to vascular infection by Verticillium dahliae. Plant Pathol. 59:130-138.

Penrose, D. M., and Glick, B. R. 2003. Methods for isolating and characterizing ACC deaminase-containing plant growth-promoting rhizobacteria. Physiol. Plant. 118:10-15.

Petrou, P., Soteriou, G., Schouten, R. E., and Kyriacou, M. C. 2013. Effects of rind removal on physicochemical quality characteristics of fresh-cut watermelon [Citrullus lanatus (Thunb) Matsum \& Nakai] during cold storage. Int. J. Food Sci. Technol. 48:357-362.

Pfaffl, M. W. 2001. A new mathematical model for relative quantification in real-time RT-PCR. Nucleic Acids Res. 29:e45. 
Pieterse, C. M. J., Van Pelt, J. A., Ton, J., Parchmann, S., Mueller, M. J., Buchala, A. J., Métraux, J. P., and Van Loon, L. C. 2000. Rhizobacteriamediated induced systemic resistance (ISR) in Arabidopsis requires sensitivity to jasmonate and ethylene but is not accompanied by an increase in their production. Physiol. Mol. Plant Pathol. 57:123-134.

Pieterse, C. M. J., van Wees, S. C., van Pelt, J. A., Knoester, M., Laan, R., Gerrits, H., Weisbeek, P. J., and van Loon, L. C. 1998. A novel signaling pathway controlling induced systemic resistance in Arabidopsis. Plant Cell 10:1571-1580.

Primrose, S. B. 1977. Evaluation of the role of methional, 2-keto-4methylthiobutyric acid and peroxidase in ethylene formation by Escherichia coli. J. Gen. Microbiol. 98:519-528.

Puhalla, J. E., and Mayfield, J. E. 1974. The mechanism of heterokaryotic growth in Verticillium dahliae. Genetics 76:411-422.

Robison, M. M., Shah, S., Tamot, B., Pauls, K. P., Moffatt, B. A., and Glick, B. R. 2001. Reduced symptoms of Verticillium wilt in transgenic tomato expressing a bacterial ACC deaminase. Mol. Plant Pathol. 2:135-145.

Saleem, M., Arshad, M., Hussain, S., and Bhatti, A. S. 2007. Perspective of plant growth promoting rhizobacteria (PGPR) containing ACC deaminase in stress agriculture. J. Ind. Microbiol. Biotechnol. 34:635-648.

Sambrook, J., Fritsch, E. F., and Maniatis, T. 1989. Molecular Cloning: A Laboratory Manual, 2nd Ed. Cold Spring Harbor Laboratory Press, Cold Spring Harbor, NY, U.S.A.

Sinha, A. K., and Wood, R. K. S. 1968. Studies on the nature of resistance in tomato plants to Verticillium albo-atrum. Ann. Appl. Biol. 62:319-327.

Tjamos, E. C. 1989. Problems and prospects in controlling Verticillium wilt. Pages 441-456 in: Vascular Wilt Diseases of Plants. Tjamos, E. C., and Beckman, C., eds. Springer, Berlin.

Toklikishvili, N., Dandurishvili, N., Vainstein, A., Tediashvili, M., Giorgobiani, N., Lurie, S., Szegedi, E., Glick, B. R., and Chernin, L. 2010. Inhibitory effect of ACC deaminase-producing bacteria on crown gall formation in tomato plants infected by Agrobacterium tumefaciens or A. vitis. Plant Pathol. 59:1023-1030.

Tsang, D. L., Edmond, C., Harrington, J. L., and Nühse, T. S. 2011. Cell wall integrity controls root elongation via a general 1-aminocyclopropane-1carboxylic acid-dependent, ethylene-independent pathway. Plant Physiol. 156:596-604.

Tsuchisaka, A., Yu, G., Jin, H., Alonso, J. M., Ecker, J. R., Zhang, X., Gao, S., and Theologis, A. 2009. A combinatorial interplay among the 1aminocyclopropane-1-carboxylate isoforms regulates ethylene biosynthesis in Arabidopsis thaliana. Genetics 183:979-1003.

Tzeng, D. D., and DeVay, J. E. 1984. Ethylene production and toxigenicity of methionine and its derivatives with riboflavin in cultures of Verticillium, Fusarium and Colletotrichum species exposed to light. Physiol. Plant. 62:545-552.

Tzeng, D. D., and Devay, J. E. 1985. Physiological responses of Gossypium hirsutum L. to infection by defoliating and nondefoliating pathotypes Verticillium dahliae Kleb. Physiol. Plant Pathol. 26:57-72.

Tzima, A., Paplomatas, E. J., Rauyaree, P., and Kang, S. 2010. Roles of the catalytic subunit of cAMP-dependent protein kinase $\mathrm{A}$ in virulence and development of the soilborne plant pathogen Verticillium dahliae. Fungal Genet. Biol. 47:406-415.

Tzima, A. K., Paplomatas, E. J., Rauyaree, P., Ospina-Giraldo, M. D., and Kang, S. 2011. VdSNF1, the sucrose nonfermenting protein kinase gene of Verticillium dahliae, is required for virulence and expression of genes involved in cell-wall degradation. Mol. Plant-Microbe Interact 24: 129-142.

Tzima, A. K., Paplomatas, E. J., Tsitsigiannis, D. I., and Kang, S. 2012. The $\mathrm{G}$ protein $\beta$ subunit controls virulence and multiple growth- and development-related traits in Verticillium dahliae. Fungal Genet. Biol. 49:271-283.

Van de Poel, B., and Van Der Straeten, D. 2014. 1-aminocyclopropane-1carboxylic acid (ACC) in plants: More than just the precursor of ethylene! Front. Plant Sci. 5:640.

Vanderstraeten, L., and Van Der Straeten, D. 2017. Accumulation and transport of 1-aminocyclopropane-1-carboxylic acid (ACC) in plants: Current status, considerations for future research and agronomic applications. Front. Plant Sci. 8:1-18.

van Loon, L. C., Geraats, B. P. J., and Linthorst, H. J. M. 2006. Ethylene as a modulator of disease resistance in plants. Trends Plant Sci. 11:184-191.

van Wees, S. C. M., Luijendijk, M., Smoorenburg, I., van Loon, L. C., and Pieterse, C. M. J. 1999. Rhizobacteria-mediated induced systemic resistance (ISR) in Arabidopsis is not associated with a direct effect on expression of known defense-related genes but stimulates the expression of the jasmonate-inducible gene Atvsp upon challenge. Plant Mol. Biol. 41:537-549.

Wang, C., Knill, E., Glick, B. R., and Défago, G. 2000. Effect of transferring 1-aminocyclopropane-1-carboxylic acid (ACC) deaminase genes into Pseudomonas fluorescens strain $\mathrm{CHA} 0$ and its gacA derivative CHA96 on their growth-promoting and disease-suppressive capacities. Can. J. Microbiol. 46:898-907.

Weingart, H., Ullrich, H., Geider, K., and Völksch, B. 2001. The Role of ethylene production in virulence of Pseudomonas syringae pvs. glycinea and phaseolicola. Phytopathology 91:511-518.

Wiese, M. V., and Devay, J. E. 1970. Growth regulator changes in cotton associated with defoliation caused by Verticillium albo-atrum. Plant Physiol. 45:304-309.

Xu, S.-L., Rahman, A., Baskin, T. I., and Kieber, J. J. 2008. Two leucinerich repeat receptor kinases mediate signaling, linking cell wall biosynthesis and ACC synthase in Arabidopsis. Plant Cell 20: 3065-3079.

Yoon, G. M., and Kieber, J. J. 2013. 1-Aminocyclopropane-1-carboxylic acid as a signalling molecule in plants. AoB Plants 5:plt017.

Zhu, P., Xu, L., Zhang, C., Toyoda, H., and Gan, S. S. 2012. Ethylene produced by Botrytis cinerea can affect early fungal development and can be used as a marker for infection during storage of grapes. Postharvest Biol. Technol. 66:23-29.

Zhu, P., Xu, Z., Cui, Z., Zhang, Z., and Xu, L. 2017. Ethylene production by Alternaria alternata and its association with virulence on inoculated grape berries. Phytoparasitica 45:273-279. 